University of Louisville

ThinkIR: The University of Louisville's Institutional Repository

$5-2014$

\title{
Academics and activism : a comparative study of contemporary historical writings on same-sex sexuality and LGBT activists in the Middle East.
}

Lauren Copeland

University of Louisville

Follow this and additional works at: https://ir.library.louisville.edu/etd

Part of the Feminist, Gender, and Sexuality Studies Commons

\section{Recommended Citation}

Copeland, Lauren, "Academics and activism : a comparative study of contemporary historical writings on same-sex sexuality and LGBT activists in the Middle East." (2014). Electronic Theses and Dissertations. Paper 276.

https://doi.org/10.18297/etd/276

This Master's Thesis is brought to you for free and open access by ThinkIR: The University of Louisville's Institutional Repository. It has been accepted for inclusion in Electronic Theses and Dissertations by an authorized administrator of ThinkIR: The University of Louisville's Institutional Repository. This title appears here courtesy of the author, who has retained all other copyrights. For more information, please contact thinkir@louisville.edu. 


\title{
ACADEMICS AND ACTIVISM: A COMPARATIVE STUDY OF CONTEMPORARY HISTORICAL WRITINGS ON SAME-SEX SEXUALITY AND LGBT ACTIVISTS IN THE MIDDLE EAST
}

\author{
By \\ Lauren Copeland \\ B.A., University of Kentucky, 2009
}

\begin{abstract}
A Thesis
Submitted to the Faculty of the

College of Arts and Sciences of the University of Louisville in Partial Fulfillment of the Requirements for the Degree of
\end{abstract}

Master of Arts

Department of Women's and Gender Studies

University of Louisville

Louisville, KY

May 2014 

ACADEMICS AND ACTIVISM: A COMPARATIVE STUDY OF CONTEMPORARY HISTORICAL WRITINGS ON SAME-SEX SEXUALITY AND LGBT ACTIVISTS

IN THE MIDDLE EAST

\author{
By \\ Lauren Copeland \\ B.A., University of Kentucky, 2009
}

A Thesis Approved on

April 21, 2013

by the following Thesis Committee:

\begin{tabular}{c}
\hline $\begin{array}{c}\text { Dr. Malissa Taylor } \\
\text { Thesis Director }\end{array}$ \\
\hline Dr. Nancy Theriot \\
\hline Dr. Catherine Fosl
\end{tabular}




\section{ABSTRACT \\ ACADEMICS AND ACTIVISM: A COMPARATIVE STUDY OF CONTEMPORARY HISTORICAL WRITINGS ON SAME-SEX SEXUALITY AND LGBT ACTIVISTS IN THE MIDDLE EAST}

\section{Lauren Copeland}

April 21, 2014

In the past several years, there has been an abundance of U.S. news stories outlining the widespread oppression of queer people in the Middle East. At the same time, some international human rights organizations have focused all attention on LGBT asylum seekers, implying that the only course of action for queer people in the Middle East is to flee.

However, contemporary historical writers on same-sex sexuality demonstrate that the history of same-sex desire and behavior in the Middle East is incredibly nuanced and has changed greatly over time. Additionally, LGBT activists in the Middle East work from within their communities to create changes that will positively affect queer people. While historical scholars and activists outside the academy often have very different projects and understandings of same-sex sexuality, both projects are connected and influence one another. In this thesis, I compare the primary activist projects of historical scholars of same-sex sexuality and LGBT activists in that region. I show that both historians and activists deal with questions of whether there is a universal or transhistorical queer subject and how past people and past sexualities should be understood and used in the present. 


\section{TABLE OF CONTENTS}

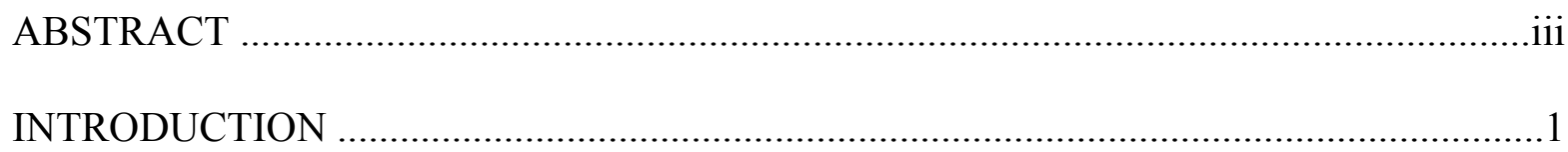

CHAPTER ONE: ACTIVIST PROJECT OF CONTEMPORARY HISTORICAL

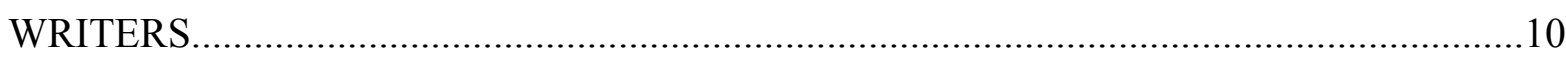

Role of the university in public life........................................................................11

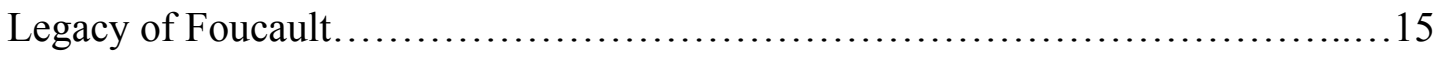

Contemporary Historical Writers Who Do Not Directly Address the Present..........19

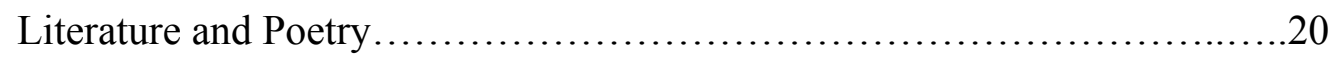

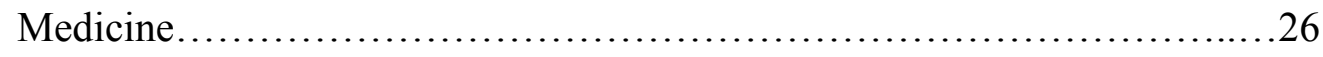

Law...................................................................... 31

A Bridge to the Present: Writing about Modernity..................................36

CHAPTER TWO: ADDRESSING CONTEMPORARY QUEER PEOPLE...................42

LGBT Activism and Heteronormalizing the Middle East...........................43

A Universal Subjectivity Towards Social Activism..............................48

Gender and Same-Sex Sexuality.............................................5

CHAPTER THREE: LGBT ACTIVIST PROJECTS ...................................57

Methods for Choosing Organizations..........................................59

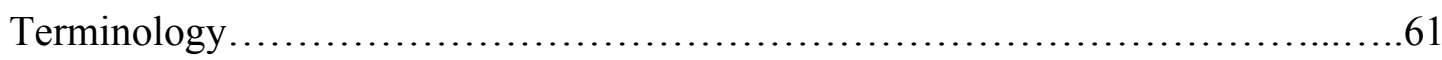

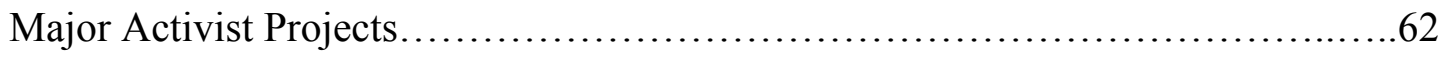

Linking the Past to the Present............................................62 
Visibility...........................................................

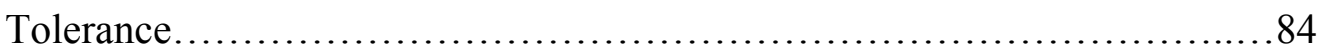

Israel/Palestine: Pinkwashing and Homonationalism...........................91

CONCLUSION ...............................................................99

REFERENCES........................................................... 104

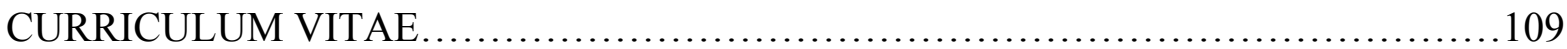




\section{INTRODUCTION}

In Samar Habib's Female Homosexuality in the Middle East, the historian examines medieval female same-sex sexuality and argues that many same-sex practices in the past are quite similar to those in the present. She suggests that understanding these similarities can aid contemporary LGBT people in the Middle East whose sexual identities are seen as invalid products of the West. While former Iranian president Mahmoud Ahmadinejad has been frequently cited and understood as ridiculous for saying that there are "no gays" in Iran, many individuals do believe that there are no LGBT people in the Middle East, and they must not be understood as purely ridiculous. ${ }^{1}$ In response to these claims and prejudiced views of LGBT people, multiple LGBT activist groups have used Habib's writings about same-sex sexuality in order to argue for an historically based same-sex identity.

Members of Aswat, a Palestinian lesbian group, apply Habib's writing in their online literature in order to refute claims that their queer identities are influenced entirely by Western constructs. For Aswat members, Habib's examination of medieval women who had sex exclusively with other women is important in demonstrating that their contemporary

\footnotetext{
${ }^{1}$ Sewell Chan, "Iranian Leader, Calling Introductory Remarks Insulting, Addresses Columbia," New York Times, September 24, 2007, http://cityroom.blogs.nytimes.com/2007/09/24/protests-at-columbia-over-iran-leadersspeech/
} 
identities are legitimate and authentic. ${ }^{2}$ According to Habib, this authenticity is important in the face of both those in the Middle East who see same-sex sexuality as a set of harmful acts that do not belong in that region and Western scholars themselves who agree that "homosexuality" is a Western construct. ${ }^{3}$

The relationship between Habib and Aswat is important because it demonstrates some of the ways in which scholarly historical writing and activism outside the academy are deeply connected. In her examination of female same-sex sexuality throughout history, Habib addresses contemporary LGBT individuals who may find her work useful. At the same time, Aswat members find value in scholarly work that speaks to individuals in their region who behaved and loved in ways that mirror their own lives. While this case demonstrates the clearest connection between activism and scholarship, LGBT activism and contemporary historical writing about same-sex sexuality in the Middle East is connected through a larger framework. In my work, I illustrate how activism outside the academy is related to contemporary historical scholarship and demonstrate the tensions that arise from this relationship. I also examine the activist projects of individuals inside and outside the academy and show how LGBT activists in the Middle East respond to historical writings on same-sex sexuality in that region. Additionally, I examine why academics and activists treat the past the way that they do.

The primary aim of this work is to identify the major projects of contemporary historical scholars of same-sex sexuality and LGBT activists in the Middle East and compare these projects. I show how historical works may reflect, elucidate, and have a bearing on

\footnotetext{
2 "Information and Publication," Aswat, http://www.aswatgroup.org/en/content/information-publication.

${ }^{3}$ Samar Habib, Female homosexuality in the Middle East: histories and representations (New York: Routledge: 2007), 146-47
} 
current activist work and LGBT people in the Middle East. I argue that the primary activist project of contemporary historical writers of same-sex sexuality in the Middle East is to demonstrate the nuances in past same-sex behavior, desire, and understanding in a way that rejects a universal or transhistorical queer subject and restores autonomy to people of the past. I also argue that LGBT activists reject this project and use historical writings and the language of universal human rights to claim a transhistorical queer subject that works against discrimination and outlines a valid LGBT identity.

In the past decade, there have been several important scholarly works on same-sex sexuality in the Middle East that have rejected past Orientalist notions of that region. While Orientalists viewed the Middle East as at first depraved and full of "homosexuals" and then uniformly repressed, contemporary historians view understandings of same-sex sexuality in that region as much more complex. ${ }^{4}$ Many historical writers such as Walter Andrews, Mehmet Kalpakli, and Dror Ze'evi work to explain sexual typologies and cultural scripts in order to contextualize same-sex desire and behavior and explain nuances in understanding of same-sex sexuality. Additionally, Khaled El-Rouayheb argues that "homosexuality" as it is currently understood did not exist in the Ottoman period in which he explores. These writers are informed by Foucault's work, which outlines a sexuality that does not exist through time and space but is culturally constructed. Therefore, each scholarly writer works to contextualize instances of same-sex sexuality and describe fine distinctions found throughout history.

In the first chapter, I analyze several contemporary historians who are part of a specific and nuanced conversation in the field of Middle East history. These scholars write

\footnotetext{
${ }^{4}$ Khaled El-Rouayheb, Before homosexuality in the Arab-Islamic world, 1500-1800: Khaled El-Rouayheb (Chicago: University of Chicago Press, 2005), 2-3.
} 
about understandings of same-sex sexuality from the start of Islam through the eighteenth or nineteenth century. Some scholars specifically focus on the Ottoman Empire, which lasted from 1516 until World War I, while others concentrate on medieval history before that. However, all scholars in this study ground their work in primary sources and use an historical framework that views the past as disconnected from the present in order to guide their work. While the Middle East may seem like a large and difficult to define region, contemporary historical writers of sexuality are very much in conversation with one another and are part of a compelling field. Therefore, once one begins to read works by scholars such as Afsaneh Najmabadi and El-Rouayheb, it becomes clear that those who study same-sex sexuality in the Middle East are engaged with one another's work and contribute to a growing field of study. While scholars examine a large time span and a vast amount of physical space, they are all attempting to explain how same-sex sexuality was understood and practiced in the past and how and why discourse on sexuality changed over time.

My method for choosing historical scholars is based upon an examination of prominent voices in the discipline of Middle East scholarship about same-sex sexuality. I examine scholars who are the most influential or important voices in their field and explain the ways in which they understand same-sex sexuality and the importance of giving the past its autonomy. I define this autonomy as a way of viewing historical writing as important for the sake of scholarship itself and being unconcerned with contemporary understandings and concepts when writing about the past. Though several writers and scholars outside the field of history such as anthropologists and journalists have written about same-sex sexuality in the Middle East, I focus on those who are trained in historical scholarship and are steeped in understandings of Middle East history. Similarly, my methods for choosing LGBT 
organizations are based upon an examination of influential Middle East- based organizations that address issues of same-sex sexuality. These methods will be further explained in the final chapter.

Though the historical project to provide the past its autonomy usually means that historians address only past people, some historians address those in both the past and present. In this study, Habib and Joseph Massad work in between historical writers who address the pre-modern Middle East and contemporary LGBT activists. While they examine same-sex sexuality at various times in the past, they also view contemporary LGBT people in the Middle East as important and worthy of study. Though Massad continues to give the past its autonomy, Habib sees same-sex sexuality in the past as much like that in the present and works towards an idea of a transhistorical and universal queer subject. I address these projects in the second chapter and illustrate how each historian employs a particular framework and understanding of history.

While there is much historical literature about same-sex sexuality in the Middle East, there is far less scholarly work that is concerned with contemporary LGBT activism in that region. Though historians argue that same-sex sexuality in the past is very unlike that in the present, scholars do not typically address the desires and behaviors of those who are in contemporary same-sex relationships. However, though understandings of same-sex sexuality have changed greatly over time, many LGBT people themselves do wish to link the past to the present. As discussed above, members of organizations like Aswat view historical writings about same-sex sexuality as important in legitimizing their same-sex identities. While most historical writers delineate past and present sexuality as disconnected, many LGBT activists in the Middle East view historical evidence of same-sex behavior and desire 
throughout history as important to claiming their own identities. For these activists, if samesex behavior has always existed in the Middle East, it may be more legitimately Middle Eastern. Additionally, though historical writers do not often address contemporary LGBT activists, their writings can have a real bearing on the lives of LGBT individuals. By creating knowledge and discussing change over time, historians often influence those inside and outside the academy. This can be understood through the work of LGBT activists in the Middle East who must react to and employ historical scholarly writings about same-sex sexuality.

In the third chapter, I explore how the activist projects of linking the past to the present, gaining visibility, and creating tolerance for LGBT people work within a framework that attempts to illustrate a universal and transhistorical LGBT subject. This analysis may be viewed as the end of a trajectory that begins with contemporary historical writers. As stated above, contemporary historical writers are part of an activist project that attempts to provide the past autonomy and works against a universal or transhistorical queer subject. Habib and Massad respond to this historical project in varying ways and serve as a bridge between historical writers who do not address the past and contemporary LGBT activists. Finally, LGBT activists place themselves as part of a history of same-sex identified and practicing people in the Middle East. They often appropriate historical writings or argue for a transhistorical same-sex sexuality in order to claim a valid LGBT identity. While historical writers do not often directly address contemporary LGBT people in the Middle East, it is clear that each piece of this trajectory is connected and should be discussed in relation to the other pieces. 
One of the most difficult aspects of a study that connects historical writings of samesex sexuality with contemporary LGBT individuals is attempting to find the correct terminology to discuss such varying sexuality. The word "homosexuality" is a modern term that describes a specific phenomenon using medical language. Therefore, it would be inaccurate to use this term to describe individuals in pre-modern eras. Contemporary words like "gay" and "lesbian" describe modern identities that should not be applied to individuals in the past or those in the present who do not identify that way. Additionally, the word "queer" describes both an identity and a deviation from the norm. However, aside from the problem of past people not identifying as queer, same-sex sexuality may not have always been viewed as a deviation from sexual norms. Therefore, I will use the term "same-sex sexuality" in order to describe sexual behavior and desire between two men or two women that was understood in a variety of ways over time. This term is not a stand-in for "homosexuality" because it does not describe a specific concept created during a specific point in time to define a particular phenomenon. At the same time, however, this term is flawed because there has not always been an assumption of men and women as different sexes. In some pre-modern medical contexts, a "one-sex" model was used in which women were seen as imperfect versions of men. ${ }^{5}$ Still, given the many barriers to finding appropriate terminology, "same-sex sexuality" appears to be the most accurate term.

Same-sex sexuality will also be the primary term used when describing contemporary LGBT projects. I will further explain my use of terminology when considering LGBT groups in the final chapter. It is important to understand that while this term does not fully consider every individual and project within LGBT organizations, it is the most accurate term for this

\footnotetext{
${ }^{5}$ Dror Ze'evi, Producing desire changing sexual discourse in the Ottoman Middle East, 1500-1900, (Berkeley: University of California Press: 2006), 23
} 
comparative study. The historical scholars that are examined in the first chapter consider same-sex behavior and desire at particular points in history and argue that understandings of same-sex behavior and desire in the past are very different from those in the present. Their primary projects deal with same-sex sexuality, and issues of pre-modern intersex or transgender individuals are not part of those projects. Additionally, attempts to connect the past to the present by LGBT organizations focus on same-sex behavior and are interested in sexual practices and relationships between two men or, more rarely, two women. When working towards a universal and transhistorical queer subject, these organizations are interested exclusively in same-sex sexuality. Though members of LGBT organizations are inclusive in name and sometimes in work on behalf of all LGBT people, their focus lies on understandings of same-sex sexuality. Therefore, this work will use the concept of same-sex sexuality to discuss both historical studies and contemporary activist projects. This project is limited in its lack of analysis of contemporary transgender, intersex, and other queer individuals in the Middle East. However, I hope to include this analysis in future studies.

My work attempts to fill a gap in scholarship that fails to address connections between scholars and activists or to view LGBT organizations in the Middle East as worthy of historical study. While it is important to examine historical scholars of same-sex sexuality as separate from present concerns, it is equally important for feminist scholars to understand the implications of that scholarship on LGBT individuals and organizations. Feminist scholarship is often concerned with bringing attention to voices that are silenced or unheard within the academy and elsewhere. Particular voices and projects within the academy are often viewed as the most legitimate and important while others are seen as unable to create knowledge and unworthy of serious study. Within the field of Middle East history, the voices 
of women have often been left out as both creators of knowledge and subjects of study.

Often, when women have been written about, it is only in relation to men. Additionally, it has historically been men who have controlled what types of history have been written and by whom. Similarly, the voices of LGBT individuals have frequently been absent from academic study. While many LGBT organizations in the Middle East have been created only in the last few years, there has been very little scholarship that takes these activists' concerns seriously and examines organizations individually.

In my work, I show that LGBT individuals and organizations in the Middle East are closely linked to historical writings about same-sex sexuality and are themselves an important subject of scholarly study. Though there are many tensions between academic and activist projects, both projects are connected through a larger framework. This framework is concerned with the question of whether there is a universal and transhistorical queer subject and how same-sex sexuality should be understood within various contexts. My comparative effort works to link these projects and to demonstrate the importance of historical writing outside the academy. Most importantly, this project illustrates the necessity of understanding activism and scholarship as two pieces of an interconnected whole. 


\section{CHAPTER ONE: ACTIVIST PROJECT OF CONTEMPORARY}

\section{HISTORICAL WRITERS}

As creators of knowledge and teachers of the past, historical writers have great power in shaping how the past is understood and how the present differs from the past. The way in which historians understand and write about the past is always political whether or not it is consciously so and must be understood within the context in which it was written. Historical writing is not objective, and both historical writing and writer are influenced by time and social location. Additionally, all historians are activists in their advocacy of a particular theory or way of understanding an issue or concept as well as in the ways that their advocacy is politically influenced. In the field of history, all scholars are activists in the sense that they have ideas about how history should be written and understood.

In this chapter, I examine contemporary historical writers of same-sex sexuality in the Middle East and describe and analyze their activist projects. I identify the important activist questions that drive academic writers and show how these questions are understood and articulated. I argue that contemporary historical writers of same-sex sexuality work to give the past autonomy and reject the concept of a universal queer subject. I also argue that this framework is used to highlight nuances in ideas and understandings of same-sex behavior over time. While these writers vary in their understandings of the past, each works with great attention to nuance and an awareness that ideas and practices in the past are much different 
from those in the present. Despite these differences, historical writing can have a great influence on LGBT individuals and movements in the Middle East.

\section{Role of the university in public life}

Historians within the academy have several functions in public life such as shaping dominant discourses about the past, promoting dialogue, helping the public make sense of political and cultural events that have shaped the present, and creating change. Those within the academy have the power to explain the historical processes that have led individuals, communities, and nations to the places that they now occupy and to illustrate that the way individuals currently live is not the way they lived in the past and is therefore subject to change. There is often a dichotomy in the academy between the sciences and the humanities concerning who creates technological and practical knowledge and who gives meaning to history and culture in a less practical sense. ${ }^{6}$ However, the university as a whole has an active role in creating and interpreting knowledge. Though historians are not always seen as practical, their creation and interpretation of knowledge has great power within public life.

Whether or not historians think of themselves as activists, historical research and writing has value in public life and shapes the way that people think about their actions and the actions of people in the past. Historian Anthony Grafton writes, "Historians of everything from drought in ancient Egypt to the economy of modern China do, in fact, have knowledge that matters- knowledge based on painstaking analysis of hard sources, which they convey to students and readers as clearly and passionately as can be managed."7 Grafton is responding to accusations that knowledge created within the university is esoteric and that historical

\footnotetext{
${ }^{6}$ Richard E. Lee, Immanuel Maurice Wallerstein, and Volkan Aytar, Overcoming the two cultures: science versus the humanities in the modern world-system, Boulder, Colo: Paradigm Publishers, 2004.

${ }^{7}$ Anthony Grafton. "History under attack," American Historical Association, Dec. 28, 2010, http://www.historians.org/perspectives/issues/2011/1101/1101pre1.cfm.
} 
writing has little practical application within public life. He argues that research gathered by university historians can create change and is often used by public historians who engage more directly with those outside the academy. However, Grafton also argues that the very act of doing historical research and searching for knowledge matters and contributes to the well being of the greater culture. ${ }^{8}$

Historical writers of same-sex sexuality have a direct and indirect influence on public life, but they are divided on the ways that they understand their influence. Public intellectuals, who will be examined in the second chapter, explicitly state their role within public life and address the ways in which they wish to create change and dialogue outside of the academy. These writers often wish to create public debate about issues of sexuality and the ways in which international LGBT organizations operate in the Middle East. They also wish to transform the way that historical questions are framed and to challenge historians and those outside of the academy to rethink normative categories like "Islam" and "the West." Other public historians take a social justice standpoint and focus on the need for greater protections for LGBT individuals in the Middle East. They also interact with those outside the academy through interviews, meetings with community members, and the active role of teaching and encouraging particular behaviors and tactics. All of these public intellectuals are aware of their influence in public life, and they use historical research and their place within the university as a tool to engage and create change outside of the academy.

The majority of the writers I examine do not self-consciously write about their place as historians within public life or their influence outside of the university. While these writers

\footnotetext{
${ }^{8}$ Ibid.

9 Joseph Masad, "The Empire of Sexuality, An Interview with Joseph Massad," Jadaliyya, last modified March 5, 2013, http://www.jadaliyya.com/pages/index/10461/the-empire-of-sexuality_an-interview-with-joseph-m.
} 
do not address contemporary LGBT activists or directly urge political change within public life, their work is extremely political and has political and theoretical consequences within public life. The way that people think about the past influences the way that they think and act politically and how they see themselves within their specific societies. Historical writing can influence the ways in which individuals understand their own identity and the way that they choose to identify others. Writings on the history of sexuality can shape dominant narratives about individuals within a particular culture or about how an entire geographic region is understood. Past Orientalist writings about sexuality in the Middle East viewed Arabs as at first decadent and then as repressed depending on changes in discourse within the West itself. These writers viewed the pre-nineteenth century Middle East as accepting and particularly suitable for "homosexuality" and saw themselves and their nations as superior to the people and practices in the Middle East. ${ }^{10}$ Orientalist writings had great influence on the ways in which those outside of the Middle East thought about that region, and the legacy of these writings continues today through patronizing and colonialist descriptions and understandings of individuals in the Middle East.

The legacy of Orientalism is particularly important to understand in the context of this study. Edward Said's 1978 Orientalism is the central text that challenged understandings of Orientalism and the dichotomy between what was considered the East and Western world. In this work, Said explores the history of European colonialism and shows the manner in which Europeans created the idea of the "Orient" as distinct from and lesser than the "Occident." He writes that this distinction has been widely accepted by scholars and has served as the basis for many theories and modes of study. He gives multiple definitions of

\footnotetext{
${ }^{10}$ Khaled El-Rouayheb, Before homosexuality in the Arab-Islamic world, 1500-1800, (Chicago: University of Chicago Press: 2005), 2-3.
} 
Orientalism including "the corporate institution for dealing with the Orient- dealing with it by making statements about it, authorizing views of it, describing it, by teaching it, settling it, ruling over it: in short, Orientalism as a Western style for dominating, restructuring, and having authority over the Orient." ${ }^{.11}$ Said argues that the "Orient" and the "West" have been historically created, in part, to provide Europe with power and feelings of superiority. However, he argues that ideas about "the oriental" are based on cultural stereotypes and racism that have worked to serve only European interests. ${ }^{12}$

Said's work is important because it shows how ideas about the Middle East as sexually crazed and morally depraved became to be seen as truths for many scholars. It also shows that the boundaries between the East and West are largely artificial and should be problematized and taken apart. ${ }^{13}$ The legacy of Orientalism can still be seen in works that unproblematically make distinctions between the East and West or view the history of the Middle East as entirely different from European history with no evidence of cultural sharing. This is especially seen in works concerning same-sex sexuality and gender in which samesex sexuality is understood to be at first rampant and then deeply repressed and in which women are exoticized. However, many of the writers examined in this study work against Orientalist writing and show that much that has been written about sexuality in the Middle East has lacked nuance and has relied on generalizations about those in that region. These writers avoid essentialist understandings of the Middle East and examine the ways in which same-sex sexuality has changed and has been understood differently over time. Though they write about the Middle East as a region, they understand that its boundaries are far from

\footnotetext{
${ }^{11}$ Edward Said, Orientalism, (New York: Vintage Books: 1994), p. 1-3.

${ }^{12}$ Ibid, p. 3-6.

${ }^{13}$ Ibid, p. 167.
} 
rigid, and the Middle East and Europe have shared in many cultural and social practices throughout history.

\section{Legacy of Foucault}

Before analyzing contemporary writers of same-sex sexuality, it is important to understand the ways in which this field is very much shaped by Michel Foucault's work. Foucault was an influential French philosopher who is credited with creating a constructionist view of sexuality in his well-known work The History of Sexuality, which was first published in the 1970s. In this three-volume piece, the philosopher explains sexuality and argues for a socially constructed idea of the concept. In this work, Foucault writes that sexuality is not a "constant" historical entity but is experienced differently depending on the place and time. ${ }^{14}$ Additionally, Foucault believed that homosexuality, like heterosexuality, was a fairly recent Western construction and that evidence of same-sex behavior, such as that found among the Greeks, is quite unlike the construction of "homosexuality" prevalent in modern Western society. ${ }^{15}$ Foucault explains his work in terms of theories a scientia sexualis, or the science of sex. He writes that in the nineteenth century, those in the West moved away from an idea of sexuality based on confession and regulating sexual acts and began to become preoccupied with explaining sex though scientific discourse. He argues that this led to the creation of scientific "truth" about sexuality and the categorization of sexual typologies into "normal," as seen in heterosexuality, and "abnormal," as seen in homosexuality. No longer did the church control the discourse about which type of sexual behavior was

\footnotetext{
${ }^{14}$ Michel Foucault, The history of sexuality, Vol. 2: The Use of Pleasure, (Random House Digital: 2012), p.4.

${ }^{15}$ Ibid, 187.
} 
permissible and impermissible but new social norms emerging from science and medicine controlled discourses about the body. ${ }^{16}$

Another influential and related Foucauldian concept is that of power-knowledge. Foucault writes in The History of Sexuality that "power is everywhere...power is not an institution, and not a structure; neither is it a certain strength we are endowed with; it is the name that one attributes to a complex strategical situation in a particular society." ${ }^{17}$ For Foucault, one place to observe power was through relationships between people. ${ }^{18}$ Important to his understanding of power is that of discourse, which refers to a conceptual apparatus through which meaning, truth, and individuals are created. Foucault also uses the idea of power-knowledge in Discipline and Punish: the Birth of the Prison to argue that power creates knowledge and, therefore, power creates truth. Thus, power and knowledge cannot be separated from one another. By creating knowledge, one is powerful. Additionally, it is through discourse that power-knowledge is created. ${ }^{19}$ He argues that since the nineteenth century, scientific discourse that claimed particular truths about society and human behavior has been used as a means of power and control. ${ }^{20}$

Foucault's work changed the discourse on sexuality enormously, and nearly all contemporary scholars of sexuality continue to reference his work. While there are some essentialist scholars of sexuality who believe that sexuality is static rather than constructed, most scholars follow Foucault's ideas about the socially constructed and historically specific

\footnotetext{
${ }^{16}$ Michel Foucault, The history of sexuality, Vol. 1. (New York: Vintage: 1990), 69-73.

${ }^{17}$ Ibid, p. 93.

${ }^{18}$ Ibid, p. 93.

${ }^{19}$ Michel Foucault, Discipline and punish: the birth of the prison, (New York: Vintage Books: 1995), 27.

${ }^{20}$ Ibid, p. 23.
} 
nature of sexuality. Rather than examining a single, innate sexuality, Foucault has allowed writers to examine many historically constructed sexualities. Jeffrey Weeks, an historian of sexuality, writes that Foucault was crucial in changing the trajectory of sexual history, and it is now widely understood that sexuality is historically constructed. ${ }^{21} \mathrm{He}$ writes, "It is no longer possible to see sex caught in the toils of nature, outside the bounds of history. It is a legitimate subject for historical investigation."22

Many historical scholars have used Foucault's concepts and ideas to guide or inspire their own research and to understand relationships of power and sexuality. For instance, many feminist historians have used Foucault's concepts of power to further their arguments. Monique Deveaux describes Foucault's influence within feminist scholarship in terms of three waves. First, she describes feminist "literature that appropriates Foucault's analysis of the effects of power on bodies." 23 Second, she writes that feminist analyses are often informed by Foucault's “agonistic model of power, in which multiple, interweaving power relations are viewed as inherently contested." 24 Finally, she writes that postmodern feminists who write about sexual and gender identity have used Foucault's ideas about sexual typologies in relation to theories about power and discourses about sexuality. ${ }^{25}$ Foucault's theories about power relationships and the idea of power-knowledge are also influential for historical researchers in understanding various systems of power. Additionally, his writings

\footnotetext{
${ }^{21}$ Jeffrey Weeks, Making sexual history, (Cambridge, UK: Polity Press, 2000), 132-134.

${ }^{22}$ Ibid, 139.

${ }^{23}$ Monique Deveaux, "Feminism and empowerment: A critical reading of Foucault", Feminist Studies. 20 (2) (1994): 223.

${ }^{24} \mathrm{Ibid}, 223$.

${ }^{25} \mathrm{Ibid}, 223$.
} 
on colonialism are useful to historians who write about colonialist projects and the power relationship between colonized and colonizers.

Despite Foucault's wide influence, scholars have not come near to reaching a consensus about his work, and his often confusing language has led to many interpretations of his ideas. In an early critique of Foucault's work, Mark Philp writes of Foucault's style and language that "They are not simply difficult, they are deliberately so." ${ }^{, 26}$ He writes that because Foucault is trying to create an entirely new discourse, the "ordinary objects of analysis and the accepted unities of thought disappear."27 Additionally, Edward W. Said, who was greatly influenced by Foucault's work, critiques Foucault's theories of power and resistance. He writes, "Foucault seemed to have been confused between the power of institutions to subjugate individuals and the fact that individual behavior in society is frequently a matter of following rules of conventions. ${ }^{28}$ In this piece, Said argues that Foucault fails to point to sites of resistance within his theories of power. Said and other critics also argue that Foucault failed to attribute proper agency to individuals. However, Foucault's deconstruction of the human subject or human condition does not allow for the universal concepts of agency or resistance that Said and many other historians desire. Additionally, while many feminist writers find Foucault's work useful, Deveaux argues that Foucault fails to consider women's specific life experiences and relationships to power. For instance, she argues that men's freedom is often contingent on "women's unfreedom.,"29

\footnotetext{
${ }^{26}$ Mark Philp, "Foucault on Power: A Problem in Radical Translation?" Political Theory.11 (1): 29-52 (1983): 30.

${ }^{27}$ Ibid, 30.

${ }^{28}$ Edward W. Said, Reflections on exile and other essays, (Cambridge, Mass: Harvard University Press, 2000), 241.

${ }^{29}$ Monique Deveaux, "Feminism and empowerment: A critical reading of Foucault", Feminist Studies. 20 (2) (1994): 228-236-237.
} 
Foucault has influenced in some way all of the contemporary writers of same-sex sexuality that I examine. Many of these writers expand upon his lines of reasoning or alter his work in certain ways. Some writers refute some of Foucault's claims, and one essentialist writer, Habib, disputes Foucault's work almost entirely. Though Foucault was a philosopher, his theories have made many contributions to the discipline of history and its body of knowledge. Additionally, while few historians accept Foucault's theories entirely, nearly every writer I discuss addresses his work. It seems that in historical writing on sexuality, Foucault's work is a necessary piece in the analysis, and all writers must place themselves according to how and to what extent they agree or disagree with him. Perhaps most importantly, Foucault's legacy has been to continue to create dialogue and debate about specific questions of sexuality and power, which is something that most of the scholars listed here continue to do.

\section{Contemporary Historical Writers Who Do Not Directly Address the Present}

The contemporary historical writers who will be examined in this chapter typically analyze three categories of writings about same-sex sexuality. These categories consist of literature and poetry, medicine, and law. I will explore how each writer deals with these categories and why writers choose particular primary documents in their analyses.

Additionally, I will show that these writers are involved in a project to give autonomy to the past rather than to try to connect the past to the present. This project is political, not outside of the field of history, but within the discipline itself. Historical autonomy can be viewed as a freedom from contemporary constructs and the ability to discuss history for the sake of scholarship alone. By giving the past its own autonomy, these writers are arguing that their historical subject must be examined independently of contemporary histories and is 
important in its own right. They reject a universal or transhistorical subject that is often found outside the field of history and which relies on an understanding of human nature or a human condition that is stable throughout time. As I will show in later chapters, the universal queer subject is particularly important to activists who work for "human rights" based on an understanding of a specific human condition. The tension between these differences in understanding is the clearest division between historical scholars and contemporary LGBT people.

\section{Literature and Poetry}

Historical literature and poetry is perhaps the most widely discussed type of writing in contemporary scholarship about same-sex sexuality. This is due in large part to the great number of poems between male writers and their typically younger male "beloveds" in the pre-modern Middle East. Walter Andrews and Mehmet Kalpakli title the period between the

fifteenth and seventeenth century in which this poetry was written most frequently "The Age of The Beloveds" and use this era to discuss issues of same-sex sexuality. Khaled ElRouayheb also focuses on love poetry of this era in order to discuss sexual typologies that were specific to particular times and places in the Middle East. Other contemporary historical writers such as Dror Ze'evi discuss less common forms of literature such as dream analysis and shadow plays. Additionally Stephen O. Murray and Will Roscoe expand their scope of study to "Arab Spain" and focus on mystical literature. Each of these works stresses the significance of language in poetry and literature and the importance of discourse in shaping practices and understandings of same-sex sexuality.

Andrews and Kalpakli and Ze'evi analyze literature and poetry about same-sex sexuality from the framework of social or cultural scripts. In The Age of The Beloveds, 
Andrews and Kalpakli focus on literary analysis to illustrate the social relations that are played out visibly in public space. They use the framework of "cultural scripting," which maintains that individuals rely on social and cultural scripts, depending on their specific social location, that help shape their behavior. They write that these scripts are "given form and shape by the way they are put into language, the ways they are talked about and understood at particular times in particular cultures." ${ }^{30}$ They also write that one can examine language in order to understand concepts of right and wrong, love, desire, and normativity. Similarly, Ze'evi's work focuses on sexual scripts as guidelines for behavior. He writes that sexual scripts "offer us a set of guidelines, which we do not necessarily follow but which allow us to recognize the parameters, the borders, within which we act and the points at which we transgress prescribed boundaries. ${ }^{״ 1}$ This framework of scripts that describe samesex sexuality suggests that views on same-sex behavior were never unified and differed even among those writing at the same time.

Andrews and Kalpakli and Ze'evi's frameworks are a departure from Foucault's work, which argues that nothing exists outside of discourse. In their analysis of social scripts, they do not wish to argue whether or not anything exists outside of cultural scripts but leave room for that possibility. Andrews and Kalpakli are informed by Foucault's work in their idea of an historically constructed sexuality and their concept of weak nominalism. This concept suggests that ideas such as homosexuality and heterosexuality are "discursive constructs," dependent on language rather than existing as natural or essential traits.

\footnotetext{
${ }^{30}$ Walter G. Andrews and Kalpaklı Mehmet, The age of beloveds: love and the beloved in early-modern Ottoman and European culture and society, (Durham: Duke University Press: 2005), 37-38.

${ }^{31}$ Dror Ze'evi, Producing desire changing sexual discourse in the Ottoman Middle East, 1500-1900, (Berkeley: University of California Press: 2006), 10.
} 
However, this framework differs from Foucault and other constructionists in Andrews and Kalpakli's statement that "we do not entirely discount the possibility that a broad range of inborn inclinations or preferences exist." ${ }^{32}$ In a similar way, Ze'evi does not discount the possibility that something exists outside of discourse. This is evident in his discussion of historical writing and the role of the historian. He writes that it is not possible to find the "historical reality of sex" from sources like Ottoman love poetry because so much of what is written is metaphor, fantasy, or distortion. ${ }^{33}$ This position suggests that the link between discourse and behavior is not entirely clear.

In their examination of Ottoman love poetry, Andrews and Kalpakli emphasize what kinds of love were permissible, how social relations were played out visibly in public space, and what was left invisible during this age. They write that in early-modern Ottoman cities, only adult men could be visible in public, and women who came into that space had to be protected or would risk being understood as prostitutes. ${ }^{34}$ These rules about visibility and public space are seen in love poetry in which the beloveds, or the objects of the poems, had to be "publically available and intellectually prepared to play the game." 35 Such rules also disqualified women, who were to remain veiled. However, in Ottoman society, young beardless men could take the passive role in relationships with older men and were seen as acceptable objects in love poems. While poets had relationships with both men and women,

\footnotetext{
${ }^{32}$ Walter G. Andrews and Kalpaklı Mehmet, The age of beloveds: love and the beloved in early-modern Ottoman and European culture and society, (Durham: Duke University Press: 2005), 12-15.

${ }^{33}$ Dror Ze'evi, Producing desire changing sexual discourse in the Ottoman Middle East, 1500-1900, (Berkeley: University of California Press: 2006), 7-8.

${ }^{34}$ Walter G. Andrews and Kalpaklı Mehmet, The age of beloveds: love and the beloved in early-modern Ottoman and European culture and society, (Durham: Duke University Press: 2005), 51

${ }^{35}$ Ibid, 55.
} 
only young men could be written about in the public context of love poetry. ${ }^{36}$ However, men could not have public sexual relationships with boys or write explicitly about their sexual interactions with them. Though sexual relationships between men and boys during this period were not usually punished, the sexual aspects of these relationships were only acceptable if kept private. ${ }^{37}$ This meant that "explicit speech about sex" was not meant for a public audience, and when men wrote explicitly about sex, it was "for the purpose of private communication between men. ${ }^{, 38}$ This point is important because it complicates ideas about visibility and accepted practice. Speech about same-sex sexuality was not either fully visible or fully hidden. Rather, certain aspects of same-sex relationships were permitted while others were not fit for public space.

In Before Homosexuality in the Arab-Islamic World, El-Rouayheb explores many of the same love poems from the Ottoman era in order to explore sexual types. He uses these sexual types to show that the concept of "homosexuality" did not exist in the early Ottoman Middle East and that same-sex behavior was understood much differently than it is today. For instance, in same-sex relationships, men in an active-insertive role were referred to as luti and those who preferred a passive-receptive role were referred to as mukhannath. ${ }^{39}$ Additionally, El-Rouayheb writes that in the early Ottoman period, male same-sex relationships were almost exclusively between an adult man and a beardless youth or amrad. These youth, also referred to as ghulam or sabi (boy) or fata, shabb or hadith

\footnotetext{
${ }^{36}$ Ibid, 49.

${ }^{37}$ Ibid, 80.

${ }^{38} \mathrm{Ibid}, 130$.

${ }^{39}$ Khaled El-Rouayheb, Before homosexuality in the Arab-Islamic world, 1500-1800, (Chicago: University of Chicago Press: 2005), 16.
} 
(male youth), were not considered to be entirely "men" culturally or socially, which was understood by their lack of facial hair. El-Rouayheb writes, "The cultural importance of beards and/or mustaches in the early Ottoman Arab East is attested by both the European travel literature and the indigenous literature. The beard or mustache was a symbol of male honor, something one swore or insulted." 40 Therefore, beardless boys were feminized in culture and literature and were often placed in the role of "coveted object." ${ }^{, 41}$ El-Rouayheb writes that both married and unmarried men courted beardless youths and that these relationships were very common. He writes that love poetry from the Ottoman period shows that while "transgenerational" relationships that conformed to certain sexual roles were the most common, there is evidence that other types of relationships, such as between two adult men or two young boys, existed. ${ }^{42}$ This finding demonstrates that while there were widely accepted sexual types, practices and understandings of same-sex sexuality were highly nuanced and could not be reduced to a single category.

In "The Obscenity of the Vizier," Frederic Lagrange goes beyond El-Rouayheb's extensive analysis of dominant sexual types, and focuses on those who transgress from these types and the ways in which all male same-sex behavior may have been connected. Lagrange writes that while most scholars stress sexual behavior and roles in pre-modern same-sex relationships, it may be possible to write about a sort of identity in which a particular gender was preferred. ${ }^{43}$ Lagrange's work focuses on tenth-century literature that

\footnotetext{
${ }^{40}$ Ibid, 26.

${ }^{41}$ Ibid, 27.

${ }^{42}$ Ibid, 28-33.

${ }^{43}$ Kathryn Babayan, and Afsaneh Najmabadi, Islamicate sexualities: translations across temporal geographies of desire, (Cambridge, Mass: Center for Middle Eastern Studies of Harvard University: 2008), 161.
} 
condemns individuals who are involved in same-sex relationships and shows that this work of satire may provide a link between those in passive and active roles towards a sort of transgressive character. ${ }^{44}$ While many contemporary historical writers of same-sex sexuality suggest that same-sex sexual behavior was part of a continuum of preferences and behaviors that could not be lumped into a single category, Lagrange argues that such a category may have been possible. Such a category was not explicitly named but may have been suggested in literary works that insulted those who preferred someone of the same gender, despite their sexual role. Lagrange writes that in tenth-century discourse, "insult may accidentally construct what it denounces, building this field of 'homosexuality,' which in theory remains unthought." 45

Lagrange's work examines a satirical text by scholar Abu Hayan al-Tawhidi that libelously attacks two viziers of effeminateness, passive sodomy, and active sodomy. Lagrange argues that the language used to insult creates heteronormalization and a "preconstruction" of the "homosexual character." ${ }^{.46}$ He shows that this work implies a preference, or possibly an exclusive preference, for young men that goes beyond what is considered normal behavior for the time. This text also implies a preference for a particular gender rather than simply a passive or active sexual role. He writes that the characterization of homosexuality is expressed only through denunciation rather than enunciation or "positive discourse." Lagrange writes that he does not intend to dispute a constructionist view of sexuality or favor an essentialist approach. Rather, he wishes to alter it. He writes that though he agrees that one cannot apply the term "homosexuality" to pre-modern people, "what is not

\footnotetext{
${ }^{44} \mathrm{Ibid}, 165$.

45 Ibid, 189.

${ }^{46} \mathrm{Ibid}, 166$.
} 
articulated is not necessarily what is inconceivable, if only in the case where the unarticulated finds its expression in the realm of insult." ${ }^{47}$ Additionally, Lagrange argues that men in the pre-modern Middle East found a link between passive and active male samesex sex and between the active male sexuality and effeminacy. He also argues that men who engaged in same-sex sexual behavior and desire may have been thought of as unique because of their interest in a particular gender. Therefore, he writes that contemporary historical understandings of same-sex sexuality may need to be altered to include more than discussions of sexual behavior. ${ }^{48}$ Like the other writers who have been discussed, Lagrange does not wish to create a transhistoric subject in which concepts of gay or straight are relevant throughout history. Instead, he wishes to create a more nuanced understanding of same-sex sexuality in the past that reaches beyond discussions of same-sex acts while allowing the past its own autonomy.

\section{Medicine}

Another important theme found throughout histories of same-sex sexuality is that of medical discourse. While same-sex sexuality was often viewed as normative between men and beardless youth throughout much of pre-modern history, medical texts worked to explain sexual practices and roles and the relationship between the body and mind. Continuing his emphasis on sexual scripts, Ze'evi analyzes how medical scripts served as guidelines for sexual behavior. He also shows how these scripts changed over time and existed alongside often conflicting sexual scripts found in literature and law. For instance, he writes that Ottoman medical scripts describe a "one-sex" model in which men and women fit within

\footnotetext{
${ }^{47}$ Ibid, 188-189.

${ }^{48} \mathrm{Ibid}, 189$.
} 
varying degrees of the same sex. Women were seen as less perfect versions of men and were to perform specific roles that highlighted their inferior status to men. Because of the one-sex model, Ze'evi argues that same-sex sexuality, or sex between two men or two women, was not implicitly differentiated in medical literature from sex between a man and a woman. $\mathrm{He}$ writes, "Having what we would now view as same-sex relations need not be a travesty, at least as far as "nature' was concerned." ${ }^{49}$ At the same time, however, there were sexual scripts that defined same-sex sexuality as deviant. In the context of the seriat, or sacred law, anal intercourse between men was categorized as liwat, and was discussed pejoratively. Though there was disagreement about how and whether anal sex should be punished, the fact that this negative sexual script existed along with less derogatory scripts is important. Individuals living in the pre-modern Middle East would have been exposed to both of these scripts, along with many others, which helped shape their lives. ${ }^{50}$

While the one-sex model often made same-sex sexuality medically normative, there were periods throughout pre-modern history in which sex between two men was seen as pathological. Ze'evi and El- Rouayheb explore ways in which sex between two men was viewed as deviant according to some medical documents. Ze'evi writes that some preOttoman medical tracts theorized that ubnah, or passive male "homosexuality," was the result of "weaker male semen." ${ }^{, 51}$ Twelfth century philosopher Fakhr al-Din al-Razi writes that men with weaker male sperm, and thus feminine characteristics, are susceptible to being a ma'bun, or a man who wishes to be penetrated. These men were thought to have differently

\footnotetext{
${ }^{49}$ Dror Ze'evi, Producing desire changing sexual discourse in the Ottoman Middle East, 1500-1900, (Berkeley: University of California Press: 2006), 23.

${ }^{50}$ Ibid, 23.

${ }^{51}$ Ibid, 37-38.
} 
shaped genitals than other men such as a smaller penis and testicles. Those who were considered ma'bun were also thought to have erogenous zones that were "closer to the anus" than other men. Al-Razi's cure for this pathology includes "heating the penis and cooling the anus... rubbing ointments on them, and bathing the genitals." ${ }^{52}$ These cures stemmed from Galenic concepts of the four humors. Additionally, men who preferred to penetrate other men were not considered pathological. ${ }^{53}$

Ze'evi writes that though al-Razi treated passive male same-sex sexuality as a disease rather than a sin, ubnah was still viewed as a shameful act during the Abbasid era, which lasted from the mid- eighth century to the mid- thirteenth. Some writers, such as Ibn SIna and Ibn Hubal, viewed passive male same-sex sexuality as a cultural problem or sin rather than a physical disease. These writers believed that men who preferred to be penetrated should be punished rather than cured. They also argued that ma'bun were not born with any sort of genetic abnormality or lack of semen but preferred penetration because they had "accustomed themselves to nonvirtuous ways and to feminine behavior." ${ }^{, 54} \mathrm{Ze}$ 'evi writes that later medical texts in the pre-Ottoman and Ottoman periods did not discuss ubnah or questions about the shameful nature of same-sex sexuality. He writes, "It seems that the early Ottoman attitude to male 'passive' intercourse was one of indifference. This was some people's preference, it was part of the spectrum of normal sexual behavior, and it was not to be considered deviant in any way." $" 55$ Because of medicine's authoritative voice in the pre-

\footnotetext{
52 Ibid, 38.

53 Ibid, 38

${ }^{54} \mathrm{ibid}, 38$.

${ }^{55}$ Ibid, 39.
} 
modern Middle East, these medical scripts were highly influential in public discourse. ${ }^{56}$ It seems logical, then, that at times when medical writings did not condemn same-sex sexuality, this type of sexuality was normative. While the term "normative" can include multiple meanings, I am referring to behavior, desire, and ideas that are generally accepted and understood as commonplace. Normative, in this case, is that which does not attempt to diverge from established sets of behavior. Additionally, Ze'evi's emphasis on the ways in which medical scripts changed over time is important in giving Ottoman era scripts and practices autonomy from contemporary sexual scripts. Ze'evi shows that same-sex sexuality in the Ottoman period cannot necessarily be lumped into a queer history because sex between two men was not always viewed as queer, or deviating from the norm.

El- Rouayheb further separates the pre-modern Middle East from the present in his exploration of medical texts. Throughout his work, El- Rouayheb argues against scholarly writing that wishes to link the "homosexuality" in contemporary times to same-sex sexual behavior in the past. He writes that Ahmad Ibn Yusuf al-Tifanshi, a thirteenth century scholar, clearly distinguishes between men who wished to penetrate boys and men who wished to be penetrated by other men. Medical works during the early Ottoman and preOttoman periods viewed only those who wished to be penetrated as pathological and often considered pederasts as similar to wine-drinkers. El- Rouayheb writes that al-Tifanshi did not understand "homosexuality," or sex between two men, as a single medical illness but as sexual types. ${ }^{57}$ El- Rouayheb also addresses arguments that those engaged in "active sodomy" were also viewed as pathological and, therefore, the modern category of

\footnotetext{
${ }^{56}$ Ibid, 16-17.

${ }^{57}$ Khaled El-Rouayheb, Before homosexuality in the Arab-Islamic world, 1500-1800, (Chicago: University of Chicago Press,: 2005), 18-19.
} 
"homosexuality" is relevant to pre-modern people engaged in same-sex relationships. These arguments are based, in part, on sixteenth century Egyptian texts that described men who liked to penetrate other men or boys according to certain physical characteristics. For instance, these men were described as having a "very tall stature with sparse beard growth" and "a snub nose." ${ }^{58}$ According to some scholars, these characteristics constituted a "peculiar type of person" similar to the "homosexual" in contemporary periods. Under this theory, the existence of a certain type of person who engaged in same-sex sexuality would dispute Foucault's argument that such an idea of homosexuality did not exist until the nineteenth century. However, El-Rouayheb argues that descriptions of the "active sodomite" refer to a specific type of behavior rather than "the possession of abnormal desires." ${ }^{, 59}$ He writes that these physical characteristics do not describe an inner condition but refer to certain behavioral traits, which are similar to being lazy or "frivolous."

El-Rouayheb acknowledges similarities in same-sex sexual behavior between the modern and pre-modern periods but works to show that medical understandings of these behaviors were quite different throughout history. Throughout both Ze'evi and ElRouayheb's works, the writers make a decision to give the past its autonomy and to encourage other historians to do the same. Though these writers understand why other scholars argue for queer or "homosexual" people in the past, Ze'evi and El-Rouayheb argue that such an understanding erases nuances in each time period. Additionally, they show that such a transhistorical view of history would fail to explain much of the change over time that occurs within discourse and culture. They suggest that to ignore subtle distinctions in

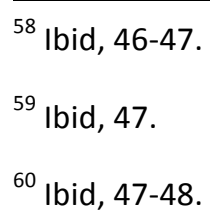


understanding and discourse would constitute poor historical writing. While Ze'evi and ElRouayheb argue against a transhistorical subjectivity in which sexuality has remained somewhat constant, they are concerned with contemporary history. El-Rouayheb writes that 'the modern term 'homosexual' hopelessly muddles certain native distinctions, and that insisting on using it in translation or paraphrase leads to serious misunderstanding." ${ }^{, 61}$ This may suggest that an historical framework that gives autonomy to the past and argues against a transhistorical subjectivity also benefits both contemporary and pre-modern history and people. As activists for a particular historical framework, Ze'evi and El-Rouayheb avoid conflating identities and practices from the past and present and attempt to create a better understanding of historical change.

\section{Law}

Legal codes and court records dealing with issues of sexuality help historians understand the ways that those in power wish to exert their influence and control over others. Often, these laws attempt to regulate private and public behavior and control what individuals do with their bodies. This often includes regulating how and with whom one can have sex. Examining the ways in which legal documents have changed over time may be useful in understanding changes in leadership and governing bodies, but these documents may not explain dominant or existing sexual practices. Therefore, most scholars of same-sex sexuality in the Middle East examine legal codes and documents alongside medical and literary sources. These scholars examine why particular laws were created and how those laws may have affected individuals over time. They also analyze the relevancy of legal codes when sexual practice and norms seemed to vary greatly from the written laws.

\footnotetext{
${ }^{61}$ Ibid, 18-19.
} 
In order to understand the importance of laws that deal with same-sex sexuality, scholars first analyze the structure of Islamic law and the ways that law was shaped. Ze'evi writes that Islamic law emerged as "the primary pillar of the faith system," and Muhammad's teachings served as the grounds for law. ${ }^{62}$ Andrews and Kalpakli write that Islamic law distinguishes between licit and illicit sex, and the sharia and sultanic law specify that zina, or sex outside of one's marriage, is "the most serious transgression." ${ }^{, 63}$ Zina is categorized under $h a d d / h u d u d$, which is a category of crimes deemed "offenses against the limits imposed by God. ${ }^{, 64}$ Written punishments for zina are severe and include being stoned to death or castrated. During the Ottoman period, penetrative sex between men and boys was often viewed as equivalent to fornication between men and women and carried an equal punishment. However, in order for zina to be punished, there had to be four "upright" male witnesses to the crime. Additionally, a charge of zina required the act of penetration, and this penetration had to be seen by witnesses in order to be punished. False accusations of zina could also be severely punished, which led witnesses to be careful in making their claims. Andrews and Kalpakli write that these laws attempt to illustrate the seriousness of zina while being reluctant to actually punish those who might engage in that behavior. Additionally, they write that during the Age of the Beloveds, there were no recorded cases of anyone being stoned to death as a punishment for committing the crime. They write that, at this time, lawmakers were probably most interested in "protecting the peace" within Muslim

\footnotetext{
${ }^{62}$ Dror Ze'evi, Producing desire changing sexual discourse in the Ottoman Middle East, 1500-1900, (Berkeley: University of California Press: 2006), 49.

${ }^{63}$ Walter G. Andrews and Kalpaklı Mehmet, The age of beloveds: love and the beloved in early-modern Ottoman and European culture and society, (Durham: Duke University Press: 2005), 271/

${ }^{64}$ Ibid, 271.
} 
communities. Extreme punishments were set to regulate behavior but did not often cross the boundary into actual practice. ${ }^{65}$

Another important function of the law deals with its relationship to power and control. Foucault writes that "the pure form of power resides in the function of the legislator; and its mode of action with regard to sex is of a juridico-discursive character., ${ }^{, 66} \mathrm{He}$ argues that by creating binaries such as licit and illicit, right and wrong, the legal system helped produce sexual mores and sexual desire itself. Ze'evi uses this framework to discuss how the two main types of law during the Ottoman period, seriat and kanun, were combined to produce a "manifestation of power" and create desire. ${ }^{67}$ Following Foucault, Ze'evi shows how legal implementations of power affect the body and how sexual desire is historically situated and connected to relations of power. He writes that the seriat and kanun, though based on different premises and outlining different punishments, came to work together as part of a single system that dealt with what was and was not permissible when it came to the body. As changes in social structure and leadership occurred, so did legislation about the body and sexuality. For instance, in the late-seventeenth century, the laws reflected the ideals of the highly religious elites who had legislative powers. As I will discuss further below, nineteenth century deployments of power through laws reflected the new-elite's attempt at creating a new nation state. At the same time, there was a Western influence that helped alter

\footnotetext{
65 Ibid, 272-274.

${ }^{66}$ Michel Foucault, The history of sexuality. Vol. 1. (New York: Vintage: 1990), 83.

${ }^{67}$ Dror Ze'evi, Producing desire changing sexual discourse in the Ottoman Middle East, 1500-1900, (Berkeley: University of California Press: 2006), 13.
} 
the way in which sexuality was written about. Laws dictating sexuality began to be discussed in euphemisms, and the sexual-legal script eventually became silent. ${ }^{68}$

In terms of producing or regulating same-sex desire and sexuality, the seriat, or sacred law, punished sex between men similarly to the way it punished zina but was seen as a more ambiguous crime. Ze'evi writes that because the Koran does not discuss same-sex sex, it was difficult for the ulema, or legal scholars, to determine how to deal with this offense. During one of the early debates concerning the shari'a and same-sex sex, Abu Hanifa, founder of the Hanafi school, argued that because "homoerotic anal intercourse" did not involve penetration of the vulva, it could not be considered hadd. In these early deliberations, the crime for penetrative same-sex sex was left undetermined. However, Ze'evi writes that these crimes "are described in the most derogatory of terms and are often accompanied by warnings of doom for those who indulge in them." ${ }^{, 69}$ So, while literary sources and medical texts show that same-sex sexuality was normative through much of pre-modern history, legal texts and opinions worked to locate same-sex sex as illicit. Additionally, in a rare discussion of same-sex sexuality between women, Ze'evi writes that "female homoerotic practices," or sihaq, were condemned rather than legally punished. This is because sex between women does not involve the insertion of a penis and could not be considered zina. ${ }^{70} \mathrm{Ze}$ 'evi argues that these legal codes did not simply discuss desire but helped create desire itself. ${ }^{71}$ His argument suggests that by defining what sex is and what sorts of sex acts are permissible, the

\footnotetext{
${ }^{68}$ Ibid, 68-74.

${ }^{69}$ Ibid, 55.

${ }^{70} \mathrm{Ibid}, 55$.

${ }^{71} \mathrm{Ibid}, 48$.
} 
law influenced the way in which people understood their sexual relationships and the ways that they articulated their desire.

While laws can be a powerful influence in creating discourse, many historians have found a wide gap between Islamic law and practice. Andrews and Kalpakli write that religious leaders urged a "theoretical legal crackdown" during the Ottoman era that established extreme punishments and laws regulating particular sexual behaviors and institutionalized surveillance in order to support these laws. However, Andrews and Kalpakli argue that these new laws existed only in the theoretical and legal realm. ${ }^{72}$ While sex between men and beardless youths was not legally tolerated, semi-public places where sexual relationships between men occurred were often permitted if the relationships there did not involve rape and were not seen as "subverting the moral character of society.",73 This was especially true if these places, often bathhouses, were controlled by elites. Additionally, legal codes dealing with sexual behavior were applied differently depending on an individual's class, and those who were elite and educated were not held as accountable for breaking these codes as those in the lower classes. ${ }^{74}$ This understanding of law versus practice is significant because it explains how public and official discourse could contradict sexual practice. This nuanced understanding of visibility also reflects Andrews and Kalpakli's project to trace carefully the ways in which sexuality was constructed and became part of a cultural script, which is different than cultural scripts about same-sex sexuality that are prevalent today.

\footnotetext{
${ }^{72}$ Walter G. Andrews and Kalpaklı Mehmet, The age of beloveds: love and the beloved in early-modern Ottoman and European culture and society, (Durham: Duke University Press: 2005), 281.

${ }^{73}$ Ibid, 285.

${ }^{74} \mathrm{Ibid}, 288$.
} 


\section{A Bridge to the Present: Writing about Modernity}

Most of the writings above have focused on pre-modern discourses about same-sex sexuality in an attempt to give autonomy to the past and illustrate nuances in sexual behavior and understanding. These writings dispute ideas of a transhistorical subjectivity and focus on the ways in which individuals behave, express desire, and understand sex and sexuality at various points throughout the pre-modern Middle East. Additionally, these scholars do not attempt to show how the past is similar to the present or to view the current century as a continuation of the past. However, scholars who write about same-sex sexuality in the contemporary period are often involved in a very different project because they are dealing with cultural scripts, sexualities, and individuals that exist in the present. While they use similar historical methods as those who write about the past, their writings often affect contemporary individuals in a way in which pre-modern histories might not. Before discussing scholars who directly address contemporary individuals, however, it is important to discuss a transitional period that began around the nineteenth century with the coming of modernity.

As the Middle East moved into the nineteenth century, cultural scripts began to change significantly, and discourse about same-sex sexuality was often silenced. Scholars who write about this transitional period serve as a bridge between those who write about the pre-modern period and those who address contemporary individuals. These scholars focus on the positions of women, the changing relationship between the Middle East and the West, and the new cultural and sexual scripts that replace or exist alongside old ones. Additionally, these writings challenge progressive narratives that maintain that the Middle East has become more advanced and better over time for the individuals who live in that region. 
Ze'evi and Afsaneh Najmabadi write about the introduction of heteronormativity into the Middle East and the conflation of womanhood with nationalism in the modern era. They show that same-sex love, once seen as normative or even expected, became to be understood as shameful and deviant. Additionally, while women were written about far less frequently than men in the pre-modern era, they became the focus of major discourses in the modern era. In Women with Mustaches and Men without Beards, Najmabadi writes that in nineteenth- century Iran, narratives about gender and public space were complicated as homosociality and same-sex sexuality became marked as backward. In the nineteenth century, nationalist interests were gripped with issues of modernity, and homosociality became essential for achieving a modern state. Najmabadi writes that much of the burden of achieving modernity was placed on women, and men and women had different roles in creating the new modern state. Najmabadi argues that while "male homoerotic affective bonds were reimagined as asexual sentiment among citizen-brothers, and men's friendships were transformed into patriotic national camaraderie... female homosociality came to be seen as deeply implicated in the production of 'the vice." ${ }^{\prime 75}$ She argues that men's same-sex sexual practices were blamed on their "ignorant" wives who occupied the unintellectual, backward private sphere. In order to end same sex sexual practices between men, heterosociality was encouraged and women were charged with leaving their homes, taking off their veils, and getting an education. ${ }^{76}$

Najmabadi's work shows the importance of visibility in governing discourses about modernity, sexuality and gender. In the nineteenth and early twentieth century, calls for

\footnotetext{
${ }^{75}$ Afsaneh Najmabadi, Women with mustaches and men without beards: gender and sexual anxieties of Iranian modernity, (Berkeley: University of California Press: 2005), 146-147.

${ }^{76}$ Ibid, 147-148.
} 
heterosociality attempted to dismantle what was considered the private sphere of ignorant women and bring them into the public sphere among men in order to further nationalist interests and show that Iran was a progressive and powerful country. Najmabadi argues that the private sphere was symbolized by the veil, and no other aspect of life was as debated as issues surrounding the veil. In many ways, the veil, which was often a symbol for women themselves, was a scapegoat for Iran's perceived backwardness and lack of progress. Taking off the veil and visibly revealing women's faces and bodies was often seen as the most important marker of progress, bringing both women and Iran into a public and visible sphere of heterosociality. Additionally, at the dawn of the modern Iranian nation, it became imperative to distinguish the visible bodies of men from those of women as a visible sign of the gender binary. Najmabadi writes that during this time, men shaved their beards and stripped away their long garments in order to look like male modern citizens. Additionally, they had to distance themselves from their shameful relationships with beardless youths, or amrads, and began growing mustaches. These physical changes were part of a widespread effort to erase a time when same-sex relationships were seen as normative and to deem samesex relationships impermissible in either the public or private sphere. In order for this effort to be successful, women had to not only cooperate in the project of visible modernity but carry the burden of modernity through their unveiled and public bodies. ${ }^{77}$

The discussion that Najmadabi highlights is important because it illustrates the complexity of social changes in Iran that have often been considered progressive, such as women's official education and unveiling and the creation of a heterosocial society. Najmabadi argues that these social changes were not created for the benefit of women within

\footnotetext{
${ }^{77}$ Ibid, 150-151.
} 
society but, in many ways, to prevent same-sex sex and "backwards" behavior within Iran. ${ }^{78}$ She shows that in the pre-modern era of homosocialism, women were allowed to live largely "unveiled" lives in terms of their freedoms of expression and writings. However, when they entered the public sphere among men, they had to veil their language and writing, removing any sexual content, and acquire a "veil of chastity" in order to be suitable for public space. She writes that entering the public space meant that women would be constrained in many ways and had to learn scientifically sanctioned behaviors and skills to make themselves into good moral citizens and women. Additionally, though women were compelled to enter the public space, men were not ready to give up or share their public space, and many women faced harassment. ${ }^{79}$ Najmabadi writes that "gender heterosocialization rescripted women's language, reconfigured women's bodily presence in public, and recoded women's wisdom and knowledge." 80 By outlining these changes, Najmabadi’s scholarly activism works not only to educate readers but to encourage a more careful approach to understandings of liberation and feminism in the Middle East. These lessons are important for feminist and progressive thinkers who have a specific idea of how to continue liberating women in the Middle East and for policy makers who are quick to encourage "liberating" laws without understanding the context of past liberation.

Similarly, Ze'evi challenges the progressive narrative that ideas about the position of women, sexuality, and society as a whole have progressed along a particular trajectory in the Middle East. Ze'evi argues that new cultural scripts rendered old scripts, or parts of old

\footnotetext{
${ }^{78} \mathrm{Ibid}, 150-154$.

${ }^{79}$ Ibid, 152-156.

${ }^{80}$ Ibid, 150-152.
} 
scripts, invisible. He writes that in the nineteenth century, Ottoman elites were highly influenced by European norms and began to be "ashamed" of expressions of love towards beardless youth. ${ }^{81}$ This was a result, in part, of European travelogues that viewed those in the Middle East as sexually promiscuous and depraved. In response to such accusations, Ottoman elites and writers attempted to uphold an image of "superior morality" in which discussions of same-sex love were silenced and heterosexual discourse was quieted. ${ }^{82}$ This led to a "purging of homoerotic material" such as books and poetry outlining the beauty and values of beardless youth. ${ }^{83}$ Ze'evi writes that by the early twentieth century, "the discourse of divine love and beauty disappeared from view." 84 Surviving works of literature by elites that referred to the beauty of beardless youth were reinterpreted as works about men's love for God. ${ }^{85}$ Additionally, new legal codes emphasized issues of violence and abuse rather than same-sex sexuality or fornication. Though the old and new legal scripts initially existed side by side, the new scripts, full of euphemisms rather than detailed descriptions of sex, eventually silenced the old ones. ${ }^{86}$

Ze'evi writes that the printing press, typically seen as a progressive invention, contributed to the silencing of old sexual scripts. As books began to be mass-produced in the nineteenth century, only the works viewed as morally acceptable for the masses were printed,

\footnotetext{
${ }^{81}$ Dror Ze'evi, Producing desire changing sexual discourse in the Ottoman Middle East, 1500-1900, (Berkeley: University of California Press: 2006), 96-97.

${ }^{82}$ Ibid, 169.

${ }^{83}$ Ibid, 97.

${ }^{84}$ Ibid, 97.

${ }^{85} \mathrm{Ibid}, 97$.

${ }^{86}$ Ibid, 75-76.
} 
and older books containing homoerotic themes disappeared into private collections or university archives. Ze'evi writes, "During a relatively short span of time an entire cultural silencing mechanism was galvanized to cleanse the discourse of anything deemed sexually improper. ${ }^{87}$ Ze'evi and Najmabadi suggest that the creation of new cultural scripts was not part of a progressive agenda to benefit or enlighten those in the Middle East but a political or nationalist project that was formed, in part, as a reaction to Western expectations of the region. Ze'evi writes that while those in the Middle East began to accept the creation of a "heteronormalized culture," individuals in the West began distancing themselves from that strict sexual binary. ${ }^{88}$

As I will discuss in the following chapters, much of the current LGBT activism in the Middle East as well as scholarship concerning same-sex sexuality deals with questions of old versus new sexual scripts and the ways in which heteronormativity has been entrenched in the region. These questions consider whether or not there is an authentic or original sexual script in the Middle East and whether or how those in the West have displaced that script. For writers and activists who grapple with contemporary same-sex sexuality, the historical work by writers such as Ze'evi and El-Rouayheb is extremely important in understanding presentday identities. While the writers who have been discussed thus far have attempted to give the past its autonomy, contemporary activists often work to bring that past into the present and to find present identities in the past.

\footnotetext{
${ }^{87} \mathrm{Ibid}, 170$.

${ }^{88} \mathrm{Ibid}, 171$.
} 


\section{CHAPTER TWO: ADDRESSING CONTEMPORARY QUEER PEOPLE}

As I have shown in the previous chapter, contemporary scholars of same-sex sexuality in the past largely work against the idea of a transhistorical gay or straight subject. These scholars are interested in granting the past its autonomy rather than attempting to connect the past to the present. This is part of a political movement within the field of history to provide the past an autonomy disconnected from the concerns of the present. The historians who will be analyzed in this chapter have very different understandings of this movement. First, Joseph Massad agrees with the general trends of the movement in his argument against a universal subject that fits along a gay-straight configuration. Massad also works to give the past its autonomy, and when he writes about past sexualities, he does so without attempting to connect the past to concerns of the present. However, Samar Habib works against the current trend in historical scholarship and argues for a universal queer subject and a view of history that sees the past as important in understanding present concerns.

Habib and Massad's work is a continuation of Najmabadi and Ze'evi's scholarship on the transitional period of the nineteenth and twentieth century that saw the emergence of new cultural scripts. Najmabadi and Ze'evi argue that these new scripts supplanted old ones and introduced a discourse of heteronormativity to the Middle East. Habib and Massad discuss the period after these scripts have been introduced, in the twentieth and twenty-first century, and deal with contemporary sexual scripts. This project is different from scholarly projects 
that have been previously discussed because Habib and Massad are writing about individuals and ideas that exist in the present. I wish to analyze how these scholars understand contemporary sexual practices and ideas and how they view current LGBT activism in the Middle East. I also wish to illustrate how their contrasting ideas about the universal queer subject affect their scholarly work.

\section{LGBT Activism and Heteronormalizing the Middle East}

In Desiring Arabs, Massad is critical of the LGBT rights movement in the Middle East and throughout much of the world as colonialist and "missionary." His work traces developments in the history of sexuality in the Middle East in a way that attempts to show that the creation of sexuality is itself an imperialist regime. Massad diverges with writers who want to merely put sexuality in an historical context and instead shows that sexuality itslef is an historical product. In his examination of the "Universal Gay" movement, he argues that Western-fueled activist groups are displacing a preexisting set of sexual norms and practices in the Middle East. He argues that there is a daily erosion of these norms and an adoption of a heteronormative framework. He blames the Universal Gay as installing this framework and removing former options for Arabs. Additionally, he argues that the new gaystraight binary imposed by LGBT activists is putting many individuals in harms way.

Massad argues that since the 1970s, those involved in the Western gay rights movement (as he refers to LGBT activism since this time) have deliberately attempted to impose Western beliefs and identities regarding sexuality on those in the Arab world. Massad analyzes particular international gay rights organizations such as the International Lesbian and Gay Association (ILGA) and the International Gay and Lesbian Human Rights Commission (IGLHRC), which he sees as universalizing gay rights. He writes that these 
organizations are composed and produced by missionary objectives that make up the "Gay International." He argues that supporters of the Gay International include Western scholars who write about the history of same-sex sexuality and particularly "homosexuality" in the Middle East and journalistic reports about gays and lesbians in the Arab and Muslim world. ${ }^{89}$ He writes that the Gay International employs antihistorical notions about the timelessness of gay and lesbian identities across all cultural boundaries and has attempted to naturalize the homo-heterosexual boundary. ${ }^{90}$ He writes, "By inciting discourse about homosexuals where none existed before, the Gay International is in fact heterosexualizing a world that is being forced to be fixed by a Western binary.",91

According to Massad's line of thinking, the institutionalization of the gay-straight binary may have also led to physical violence. Massad argues that by bringing attention to those the Gay International sees as gays and lesbians in the Middle East, it has caused a backlash of anti-gay laws and movements against those who practice any sort of same-sex sexual behavior. While he argues that upper- class Arabs and Muslims who have been fully Westernized support the Gay International, he writes that the majority of those who engage in same-sex sexuality in the Middle East do not identify as gay or lesbian. He writes that this majority is especially harmed by the government's crackdown on "homosexuality" because for the first time they will be labeled as gay or lesbian and both socially stigmatized and legally punished as such. He writes, "In espousing this liberation project, however, the Gay International is destroying social and sexual configurations of desire in the interest of

\footnotetext{
89 Joseph Massad, Desiring Arabs. (Chicago: University of Chicago Press, 2007), 160-162.

${ }^{90} \mathrm{lbid}, 167-168$.

${ }^{91}$ Ibid, 188.
} 
reproducing a world in its own image. ${ }^{92}$ This means that, under the assumption of a universal queer subject, LGBT organizations are attempting to homogenous terminology, identity, and behavior throughout the world so that it matches existing Western understandings of gay and straight. Massad suggests that this process benefits individuals in the West who gain legitimacy for their own practices and identities through the spread of a particular discourse.

Massad also argues that the heteronormalization of the Middle East disproportionately affects those who are poor and live in rural areas and are disconnected from Western wealth. He writes that such individuals are now more vulnerable to persecution by the police and legal forces. ${ }^{93}$ Additionally, he argues that because LGBT activism in the Middle East is viewed as part of an "imperialist plot," these groups incite repressive responses by the police and law officials. He writes that in past cases against those who were viewed as gay in Egypt, the Gay International only increased repression against these individuals. In his work, Massad focuses on international groups that are based in the West but attempt to intervene on behalf of those in the Middle East. These groups include the Human Rights Watch, which he views as exotifying Arabs and relying on uncorroborated stories of violence against LGBT people in the Middle East to further its cause. He argues that while these groups operate under the assumption of human rights, they are causing more harm than good. ${ }^{94}$

While LGBT organizations work on behalf of human rights, heteronormalization may also decrease sexual options and freedoms. Massad argues that the heteronormalization of the

\footnotetext{
${ }^{92}$ Ibid, 189.

${ }^{93}$ Ibid, 189.

${ }^{94}$ Ibid, 184-185.
} 
Middle East limits sexual options that existed there prior to the work of the Gay

International. For instance, he argues that previously, some men who had sexual contact with other men considered themselves as either "passive" or "receptive" sexual partners or "active" partners but did not have to choose between other men or women exclusively. However, he argues that because of the heteronormalizing of the Arab world, those who were previously considered passive are forced to identify as "homosexual or gay" and those who were considered active are forced to limit their sexual object choice to men or women and to identify as gay or straight. Massad argues that because of these coercive practices, men who had sexual contact with men without a "gay" label will no longer have access to their “previously available sexual object choice." 95

One critique of Massad's work involves his argument that LGBT organizations are responsible for heteronormalizing the Middle East. He views these organizations as aggressively attempting to universalize the Middle East during the past few decades through the discourse of human rights. ${ }^{96}$ However, as Najmabadi and Ze'evi show, heteronormative discourse was already being adopted in the Middle East by the twentieth century. In Najmabadi's analysis of nationalist discourse, she shows that, starting in the nineteenth century, individuals were encouraged to distance themselves from same-sex behavior and to exist in heterosocial spheres. Binaries between men and women and same-sex and differentsex behavior also became more rigid. ${ }^{97}$ Additionally, Ze'evi writes of the "heteronormalized

\footnotetext{
95 Ibid, 188-189.

${ }^{96}$ Ibid, 163.

${ }^{97}$ Afsaneh Najmabadi, Women with mustaches and men without beards: gender and sexual anxieties of Iranian modernity, (Berkeley: University of California Press: 2005), 150-151.
} 
culture" entrenched in the Middle East by the early twentieth century. ${ }^{98}$ He also shows that as early as the nineteenth century, same-sex sexuality between men was "frowned on" and distinguished from other types of illicit sex. ${ }^{99}$

Given these historical writings about the creation of a gay-straight binary in the Middle East, it seems that when Massad writes about heteronormalizing the Middle East, he is referring to something that has already happened. LGBT organizations have not created these norms in the Middle East but are merely reacting to them. Because there is already an expectation of heterosexuality in the Middle East, there is violence and discrimination against LGBT people and those who have sex with a same-sex partner. It seems, then, that LGBT organizations in the Middle East exist more as a reaction to the discrimination that they see there rather than as initiators of violence and discrimination. Many of Massad's critiques of LGBT organizations may be fair, including those concerning members of these organizations' attempts to label all men who have sex with men as "gay" or "homosexual." However, it is not accurate to argue that these organizations created the expectation of heterosexuality or the binary between gay and straight.

Another important critique of Massad's criticism of LGBT activism is that he lacks a solution to the problems that he identifies. Like the historians analyzed in the previous chapter, Massad works against the idea of a universal queer subject. Because of this theoretical and political standpoint, he is critical of a human rights discourse that relies on the existence of a universal subject. For Massad, the discourse of human rights is a missionary one that attempts to replace existing sexual structures rather than "liberate" those that human

\footnotetext{
${ }^{98}$ Dror Ze'evi, Producing desire changing sexual discourse in the Ottoman Middle East, 1500-1900, (Berkeley: University of California Press: 2006), 171.

${ }^{99}$ Ibid, 96.
} 
rights organizations seek to aid. ${ }^{100}$ However, Massad does not offer any solution or alternative political framework for countering this discourse. He is highly critical of LGBT activism and the discourses of human rights and universal queer subjectivity, but he does not give any indication of how to change this current state of activism and discourse. Whatever the cause of heteronormalization in the Middle East, it is clear that these norms existed in that region prior to the entry of LGBT groups. Additionally, while many individuals may not identify as gay or queer, it is also clear that many individuals do identify that way. Finally, it is apparent that violence and discrimination against LGBT people and those who have samesex sex in the Middle East is also occurring. Massad does not offer a solution for countering these existing norms and social structures and is unclear about what sort of political action he believes those inside the Middle East should take. Though Massad is an intellectual historian who analyzes ideas rather than actual practice, it is problematic that he is so critical of LGBT activism without discussing a solution or an alternative discourse.

\section{A Universal Subjectivity towards Social Activism}

While Massad's work follows the current political trends in historical scholarship, Habib's writing works against these trends. In her writing, she argues for an understanding of a transhistorical and universal queer subject and sees the past as largely consistent with present concerns. In her work on medieval female same-sex relationships, she criticizes Foucauldian views of sexuality and writes that an essentialist lens is more helpful when studying same-sex sexuality. Throughout her work, she describes the ways in which she believes that "homosexuality" existed in the Middle East throughout history and explains why that claim is important to contemporary queer people. She is an activist both in and

${ }^{100}$ Joseph Massad, Desiring Arabs. (Chicago: University of Chicago Press, 2007), 161-162. 
outside of the academy, and her work highlights many of the ways in which academics have influence outside of their individual universities or fields of study. She also departs from most contemporary scholarship on the Middle East in her criticism of social constructionism. She argues that constructionist scholars are "uncompromising" in their views, to the point where they will only describe same-sex behavior and shy away from anything that suggests same-sex identity in the pre-modern period of the Middle East. ${ }^{101}$ Throughout her work, she relies on the existence of a universal queer subject to demonstrate that LGBT individuals and organizations must be taken seriously and provided with rights and protections from discrimination.

In her work on contemporary LGBT people in the Middle East, Habib focuses on similarities throughout history rather than discrepancies. The writers who were examined in the previous chapter work to give the past autonomy and illustrate nuances in discourse over time and place. However, Habib works from a framework that attempts to connect behaviors in the past to those in the present and draw parallels between various practices. Habib argues that there is a long history of those in both the Middle East and the West who were engaged in exclusively same-sex relationships or desire and who identified based on their exclusive desire and sexual behavior towards individuals of the same sex. Habib specifically cites the existence of medieval women who were referred to as "grinders" in the Middle East and showed an exclusive preference for other women. In her analysis of primary documents, Habib analyzes medieval poems written by women that express love and sexual desire for other women. While this name suggests a behavior rather than an identity, Habib argues that there are many parallels to be drawn between grinders and present-day lesbians. This work

\footnotetext{
${ }^{101}$ Samar Habib, Female homosexuality in the Middle East: histories and representations (New York: Routledge: 2007), 63.
} 
attempts to move beyond culturally specific labels such as "lesbian" or "queer" and understand similarities in erotic attraction towards someone of the same gender that exist throughout history. Habib does this through analysis of specific medieval texts, which she sees as evidence for similarities in the past and present. ${ }^{102}$

In Islamic Texts on Female Homosexuality, Habib analyzes works of poetry that she uses to draw parallels between grinders and contemporary lesbians. In one ninth century poem by a grinder, the poet writes, "From what I have seen of her beauty-/And O how much have I seen!-/ I say glory to whomever moulded beauty from clay/To create a perfect creature made of beauty./ I came to sip from her and her extreme thirst is at a well/ If that is prohibited (Haram) then this is not lawful (Halal)" (Habib, 2009, p. 25). Habib writes that this poem is evidence for the historical compatibility of being an individual from the Middle East with same-sex sexuality. She also argues that this poet is making a political point about what should and should not be lawful (Habib, 2009, p. 25). In another poem, this time from a thirteenth century grinder, the poet writes that her lover's vagina "conceals fire with two lips that are courser than an Israelite's cow and a hunch like a hump of Thamood's camel" (Habib, 2009, p. 28). Habib writes that the poet's references to Quranic stories suggest that the woman was highly educated (Habib, 2009, p. 28-29). These points are important in attempting to demonstrate that grinding was a conscious act that was chosen, not simply a product of circumstance, but because of mindful longing for other women. Additionally, Habib attempts to show that references to religion and laws demonstrate that medieval grinders had some understanding of how their actions and lives were perceived in the larger Muslim community. She also attempts to demonstrate that grinder poetry shows how women

\footnotetext{
102 Ibid, 25-29.
} 
understood their own sexuality, which Habib aruges is very similar to the ways in which lesbian sexuality is still understood. ${ }^{103}$

Habib uses these pieces in order to directly challenge the idea that "homosexuality" is a Western import. She argues that in the past, same-sex behavior between women was practiced in the Middle East and not always seen as a taboo or something illicit. While she acknowledges that the terminology of "homosexuality" has not always existed and did not originate in the Middle East, she argues that love and erotic devotion to someone of one's own gender has existed throughout time and space. She also argues that this understanding is important when considering the current treatment of LGBT people in the Middle East. She writes that same-sex sexuality is not distinctly human and while the concepts of same-sex sexuality are culturally specific, same-sex sexuality also has important physical components. Her work assumes that same-sex sexuality is not created through discourse alone but is written on the body in some way. Habib writes, "I hope that in light of this argument, certain Western theorists might think more carefully about the care that they took in making homosexuality a Western construct- separate or discontinuous from homosexual behavior." ${ }^{104}$ Habib argues that viewing the West as the "originator of a fact of physical/organic life," or the concept of "homosexuality," only hurts those in the Middle East who practice same-sex love and sex. ${ }^{105}$

These arguments contrast greatly with those of the majority of contemporary historians in the Middle East who search for nuance and attempt to grant the past its

\footnotetext{
${ }^{103}$ Samar Habib, Female homosexuality in the Middle East: histories and representations (New York: Routledge: 2007), 25-29.

104 Ibid, 146-147.

105 Ibid, 146.
} 
autonomy. Rather than engaging with the specifics of these historical arguments, Habib attempts to disregard them and talk about something very different. She does not address the types of issues that many previously discussed historians address because those issues do not further her academic goals. Her understanding of a universal queer subject is pervasive throughout her work and allows her to argue for similarities across cultures, religions, and geographic space. While Habib understands constructionist understandings of same-sex sexuality, she argues that these views work only to disconnect what she sees as similar practices and ideas over time and do much to harm contemporary LGBT people in the Middle East.

Habib uses her understanding of a universal and transhistorical subject that experiences same-sex eroticism and love in similar ways throughout time in order to discuss contemporary LGBT activism. In addition to her scholarly work, Habib has worked with activist groups outside the academy that organize around issues of same-sex sexuality. She writes that it is important for contemporary LGBT people to understand the history of samesex sexuality in order to combat accusations that same-sex behavior is not native to the Middle East. In a 2008 lecture at the Feminist Coalition Complex in Haifa, Habib addressed a group of Palestinian queer women on educating themselves about the past and claiming their own sexual identities. Throughout the lecture, Habib discussed the importance of coming out, her idea of same-sex sexuality as natural, the fight for civil liberties for lesbians, and the dangers of internalized homophobia and concealment. ${ }^{106}$ She also discussed a project in which Aswat has collected and distributed information and literature about same-sex sexuality that has been translated into Arabic for the purpose of educating and aiding

${ }^{106}$ Samar Habib, Arabo-Islamic texts on female homosexuality 850-1780 A.D, (Youngstown, NY: Teneo Press: 2009), 12-15. 
Palestinian queer people. This literature includes translations of pre-modern literary texts on the subjects of same-sex sexuality and sexuality in general. Habib does not include the specific content of these works but writes in her endnotes that Aswat has published feminist and queer research about lesbian and "homosexual" identity. This work is intended to educate women who see themselves as lesbian or queer about same-sex behavior in the past in order to combat criticism that their identities and behaviors are inauthentic. ${ }^{107}$

During the lecture, Habib told her audience, "By publishing these writings, Aswat puts into the hands of an upcoming generation of gay and lesbian people, theories and ideas that they can use as weapons in the fight against the epistemes of patriarchal societies that seek to oppress and repress virtually everything related to sex." ${ }^{, 108}$ This statement serves as a call to action for Palestinian queer women to work against systems of law that are intended to target and punish queer people. It also emphasizes Habib's belief that individuals in the West did not change or create same-sex sexuality in the Middle East but that same-sex sexuality is native to that region. Habib's involvement with this type of activism highlights her understanding of "homosexuality" as an essentialist concept and the importance of historical writing in public space. If same-sex love and behavior are essential across time and space, then they cannot be considered foreign or inauthentic in the Middle East. Habib suggest that for LGBT people in the Middle East, this understanding has the possibility of combating the violence and discrimination that they experience. As an historian, Habib sees her role as changing discourse inside and outside the academy in order to create social change. Rather than engage with other historians' contextually specific understandings of identity and

\footnotetext{
107 Ibid, 10-11.

108 Ibid, 10-11.
} 
behavior, Habib is attempting to generate an alternative discourse, which views "homosexuality" as a universal and transhistorical phenomenon that cannot be altered by culture or space.

\section{Gender and Same-Sex Sexuality}

One of the biggest differences between Habib and Massad's work deals with the question of gendered space and the binary between men and women. Massad, like many historians discussed in chapter one, focuses primarily on men. The writings he and other historians examine are composed by men and written for and about men. In work by ElRouayheb, Ze'evi, and Andrews and Kalpakli, sexual norms and practices among men are the primary objects of examination. Writings on women are always secondary. Massad writes that the Gay International is made up of organizations led by white men and concerned with male sexuality. ${ }^{109}$ When he speaks about sexual object choice being lost in favor of a gaystraight binary, he is mourning male norms and practices being displaced, not female ones. ${ }^{110}$ However, Habib is doing something very different in her work. By focusing entirely on women and female same-sex sexuality, she is engaging in a different sort of project. By comparing grinder sexuality to contemporary lesbian sexuality, Habib is not attempting to erase a long and changing history of male same-sex sexuality but writing about something that has long been ignored.

Throughout her work, Habib suggests that the experiences of women complicate distinctions between past and present sexuality. In pre-modern historical studies about male sexuality, there is little evidence for an overarching category of male same-sex sexuality and

\footnotetext{
109 Joseph Massad, Desiring Arabs. (Chicago: University of Chicago Press, 2007), 161-162.

110 Ibid, 188-189.
} 
more information about sexual behaviors and sexual types. Additionally, as Andrews and Kalpakli's work shows, much of the sexual behavior and relationship between men was intergenerational and existed between bearded men and beardless youth. Additionally, Massad suggests that contemporary same-sex sexuality between men often relies on distinctions between "passive" and "active" rather than towards a particular gay identity. ${ }^{111}$ However, Habib's examination of grinders attempts to understand a sexuality that existed between women and which was not intergenerational and relied on an exclusive attraction towards other women. By arguing that grinders, or women who devoted their lives to other women, are much like contemporary lesbians who do the same, Habib is not necessarily erasing pre-existing sexual norms. Instead, she is pointing to experiences of women that seem to have continuity throughout history.

Because so little scholarship has examined the experiences of women in same-sex relationships in the Middle East, it is logical that Habib's work differs so greatly from the work of other historians. While it is true that nearly all primary pre-modern documents were written by men and about men, it is unfair to ignore women entirely. Though women's sexual experiences are discussed very little in primary documents, these sexual relationships did exist and did matter. In some ways, Habib's work does not engage with many contemporary scholars because these scholars are often silent on the issues she hopes to examine. In Habib and Massad's work, their interpretations of contemporary sexual practices and LGBT people are highly influenced by their understandings of gender and the relationship between men and women. In Massad's work, he understands dominant sexual discourse to be entirely male-centered and he sees no reason for discussing female same-sex sexuality. As an

111 Ibid, 188-189. 
intellectual historian, he traces dominant ideas over time and he does not see women as important in shaping these ideas. However, as a feminist historian, Habib sees the absence of women in historical writings as a problem and attempts to highlight women's experiences throughout history. Additionally, because the history of female same-sex sexuality is very different from male same-sexuality, it may be possible to discuss these histories in different ways.

In the following chapter, members of LGBT organizations discuss same-sex sexuality similarly to Habib in their understanding of a transhistorical queer subject. However, like Massad and many other historians, same-sex sexuality is often discussed through a male lens and from the standpoint of gay men. Therefore, it is important to keep in mind that gender distinctions do matter and the lived experiences of women often vary greatly from those of men even when both are discussed or discriminated against under the same label. 


\section{CHAPTER THREE: LGBT ACTIVIST PROJECTS}

While Habib and Massad both address and employ compelling arguments about LGBT activism in the Middle East directly, neither writer focuses extensively on specific activist organizations in her or his work. Habib refers to Aswat, the Palestinian lesbian organization described above, and speaks generally about activist work in the Middle East but does not spend a great deal of time discussing particular activist groups. Additionally, Massad strongly criticizes the Gay International but focuses on international LGBT organizations that have been created by those outside the Middle East rather than organizations inside the region. He also makes many general statements about these activists rather than discussing what activists write and say about themselves. However, it is important to examine the narratives created by LGBT activists and to analyze the literature and discourses that these activists produce. It is also necessary to compare the way activists understand their political projects with the way that historians view activist work outside the academy.

In this chapter, I explore several LGBT activist organizations and individuals in the Middle East who are not professional historians. I analyze how and why they treat the past the way that they do, their primary projects, and the questions that drive their work. I illustrate the ways that activists have responded to current trends in historical scholarship that argue against a transhistorical gay or straight subject. As I argue in the first two chapters, historical writing cannot be disconnected from activism. Historians influence the ways in 
which those outside the academy understand the past and construct the present. They also help individuals understand change over time, which may provide the basis and hope for continued change for some activists. Additionally, activists appropriate historical writings to further their political and activist goals, and the activists examined in this chapter often appropriate historical writings about same-sex sexuality. This analysis of LGBT activists in the Middle East is important because it widens the scope of historical study about same-sex sexuality and illustrates the overlaps and divisions between academic and activist projects.

The biggest gap between activist and academic projects involves an understanding of subjectivity and how the presence or absence of a universal subjectivity influences the way in which individuals understand the past and present. As I previously illustrated, historians who write about same-sex sexuality in the past work to give the past an autonomy and dismiss the idea of a transnational gay or lesbian subjectivity. Massad also prescribes to this project, which is why he views work like Habib's that argues for an historical lesbian subject so problematic. The LGBT activist organizations that will be analyzed typically align closer to Habib's project in their attempt to connect LGBT people in the present with those who engaged in same-sex sexuality in the past. These organizations also use the concept of "human rights" to discuss a universal subject that deserves a particular sort of treatment and understanding over space and time. Many LGBT individuals believe that human rights, as either laid out by the U.N. or understood more generally, should be applied to LGBT people in the Middle East who experience discrimination and punishments. However, both contemporary historical scholars and many individuals within the Middle East are skeptical of a universal and transhistorical gay or straight subject. Therefore, much of the activist work within the Middle East works to prove the existence of such a subject. In this chapter, I show 
that the three primary activist projects, linking the past to the present, gaining visibility, and creating tolerance for LGBT individuals, are part of a larger framework that attempts to illustrate a universal and transhistorical gay or lesbian subject. As I will demonstrate, many LGBT leaders and activists believe this transhistorical subject will bring legitimacy to LGBT-identified people in the Middle East and work to combat those who see these identities as inauthentic.

\section{Methods for Choosing Organizations}

My methods for choosing specific activist organizations deal mainly with issues of accessibility. Because I am physically removed from activism in the Middle East, I am limited to studies of online activism. However, I do not see this as a severe limitation because, from what I have read, it seems that LGBT activism in the Middle East is organized primarily through the internet. I also only chose organizations that have material in English, which does limit my access to information and writings that are only printed in Arabic. Additionally, the number of specific activist organizations I examine is limited because of censorship and safety issues that differ throughout the Middle East. Most of the LGBT organizations that operate primarily within the Middle East, both online and in terms of physical space, are Lebanese or Palestinian organizations. While there are some organizations that do work in Iraq and Iran, for instance, these organizations are headquartered in Western nations such as Canada and the UK. When analyzing various organizations, I attempt to be clear in these distinctions. Additionally, though I will use organizations with headquarters inside and outside the Middle East, I will primarily analyze organizations that were formed in the Middle East by individuals in that region. 
The reason I have chosen organizations in this way is because I am primarily interested in activism that takes place inside the Middle East by individuals from that region. While activist groups of individuals who are foreign to the Middle East, such as the International Lesbian and Gay Association, are equally worthy of study, activism by individuals from the Middle East comprises a substantially different category. As I will show, these activists often say that they are doing "authentic" work and are able to understand the needs and cultures of individuals in the Middle East in ways that those who are outside of the Middle East cannot. Within feminist discourse, the insider/outsider debate has been highly contentious with some feminists arguing that only those within a specific group are fit to research and understand that group. Some feminist scholars have also argued that researchers should not write about individuals over whom they have social power. They argue that scholars in the West have often created knowledge about colonized or nonWestern countries in order to legitimize their superiority over individuals in those countries. However, other feminist scholars argue that researchers who are "outsiders" to a social group must only state their social standpoint within their research in order to make power relationships clear. These discussions could be applied to the work of activists inside and outside of particular social groups. ${ }^{112}$ For many LGBT activists in the Middle East, insider/outsider distinctions are important. I hope to examine the importance of an "authentic" LGBT discourse from those who claim authenticity.

\footnotetext{
112 Joey Sprague, Feminist methodologies for critical researchers: bridging differences. (Walnut Creek, CA AltaMira Press, 2005), 62-63.
} 


\section{Terminology}

As I have shown in the previous chapters, terminology is both important and highly controversial when discussing issues of same-sex sexuality. Most historical scholars discuss same-sex sexuality in terms of types of relationships and sexual behavior rather than identity. These scholars do not use terms like "gay" or "lesbian" to discuss individuals in the premodern Middle East and work to illustrate why these terms are inappropriate. A few historians, such as Habib, are interested in terminology that refers to same-sex identity rather than simply behavior and use certain terms strategically and politically in their work. Outside of the academy, ahistorical terms like "lesbian" are frequently used to refer to individuals who may not have used those terms themselves. Often these terms are used to connect individuals in the past with those in the present and further a particular political project. For instance, those who employ an essentialist view of same-sex sexuality may attempt to argue for the "naturalness" of same-sex relationships by proving that there were lesbians throughout time and space. In my work, I will continue discussing "same-sex sexuality" to refer to practice and desire unless I am highlighting other terminology used by those whose work I discuss.

In terms of activist groups themselves, I will refer to these organizations as LGBT organizations rather than lesbian and gay groups. Additionally, I will refer to activists and individuals who identify as LGBT or queer as either "LGBT" or "queer." Though the term “queer" was inappropriate while discussing past people who did not deviate from the norm, LGBT activists today do deviate greatly from sexual norms. In addition, while the scholarly writers I discussed in previous chapters write about same-sex sexuality rather than an LGBT spectrum, the organizations outlined here do refer to all LGBT people (sometimes extended 
to LGBTQ or LGBTIQ). Still, it is important to note that LGBT organizations and activists write almost exclusively about same-sex sexuality or "homosexuality" rather than transgender, genderqueer, or intersex individuals. Additionally, the activist projects I examine deal primarily with same-sex sexuality and issues related to the history of same-sex sexuality in the Middle East rather than trans history or sexuality. Thus, while I will use the inclusive term "LGBT," it is important to understand that many of these groups focus primarily on same-sex sexuality.

\section{Major Activist Projects}

\section{Linking the Past to the Present}

One of the most common projects of LGBT activists is linking the past to the present in order to gain legitimacy for their sexualities and acquire an understanding of how attitudes and ideas about same-sex sexuality have changed over time. Several LGBT activists use historical writings about same-sex sexuality to further their purpose or "prove" that same-sex behavior always existed in the Middle East. Additionally, many activists appropriate historical writings about past and contemporary individuals who engaged in same-sex sexuality in order to argue for greater LGBT rights and to educate others about LGBT individuals in the Middle East. Some organization members appropriate writings by summarizing historical content on their websites and in their literature. Others create their own historical writings and cite scholarly writing in their texts.

Helem is perhaps the largest and most well known LGBT rights organization in the Middle East. The Lebanon-based group became an officially recognized organization in 2004 and works to advocate on behalf of the health and welfare of all LGBT individuals within the country. Helem's primary goal is to repeal law 534 of Lebanon's penal code, which makes 
"unnatural sexual intercourse" illegal and punishable by "up to one year imprisonment.","13 Though this law does not exclusively target LGBT individuals, it has often been used to criminalize same-sex sexuality and justify arrests of LGBT people. The law has specifically criminalized sodomy and penetrative intercourse between men. However, Helem writers say that the law does not technically include sex between women. ${ }^{114}$ Contributors on Helem's website call this law "outdated and unjust" and write that Helem's purpose is to lobby alongside other human rights organizations to repeal the law.

Helem's website is embedded in the language of human rights, and members fight for fair treatment of LGBT people as a matter of these rights. This framework is common among most LGBT organizations in the Middle East and works to create a universal subject who must be protected using a set list of universal human rights. These organizations also assume the existence of universal human rights and work only to show where those rights are not being met. Members of Helem and other organizations are either not aware or do not engage with Massad's critique of the human rights perspective. Helem's website states, "We aim to counter the lack of information (particularly in Arabic) and the pervasive misinformation about homosexuality by providing objective, factual information, initiating dialogue, and refuting common misconceptions about homosexuality." 115 One way that Helem contributors attempt to refute these misconceptions is through historical writings about samesex sexuality that are discussed or included on the organization's web page and in its publications. Helem contributors also advertise and hold events in which scholars can discuss

\footnotetext{
113 “Our Work," Helem, 2013, http://www.helem.net/node/62.

114 “Home," Helem, 2013, http://helem.net/node/22.

${ }^{115}$ Ibid.
} 
the history of same-sex sexuality in the Middle East and in which those in Lebanon can be educated on the issue.

One of Helem's methods for connecting the past with the present and discussing historical works is through Barra, its bi-quarterly magazine. Barra is published in Arabic, English, and French and covers a range of issues such as religion, sexual morality, politics, health education, history, and relationships. Barra connects people of the present to those in the past through discussions of religion, historical discussions and references, and analyses of historical works on same-sex sexuality. In Barra's fifth issue, writer Tarek Zeidan considers the availability of historical scholarship on same-sex sexuality in the Middle East. Zeidan argues that historical studies on same-sex sexuality are crucial to current activist work. He writes that there has been a serious lack of academic scholarship from within the Arab world about these issues and argues that scholarly works like Joseph Massad's Desiring Arabs are too focused on the West. He writes that these works are centered on the Middle East in relation to the West and not as its own entity. Additionally, he writes that most contemporary scholarly works on the subject are written by those who do not speak Arabic or who are not Arabs. ${ }^{116}$

Zeidan asks several questions that he believes must be addressed and writes that the "fundamental questions of Who are gay Arabs? and What are gay rights? have been largely ignored by indigenous Arab scholarship, and remain scarce, obscure, and thus unable to inform and influence activism itself. It is undeniably impressive that activists in Arab countries have managed to achieve what they could without having these question examined,

\footnotetext{
${ }^{116}$ Tarek Zeidan, “Raging Blind.” Barra, no. 05, http://www.barramag.com/wpcontent/uploads/2012/11/Barra-005.pdf.
} 
in tandem if need be, by a serious epistemological study." ${ }^{117}$ In Zeidan's short work, he attempts to show that historical writing cannot be disconnected from activist work and that the work that historians produce can be useful and important to activist goals. In his work, he does not simply use historical writings for his activist purposes but explicitly illustrates why historical works, specifically those originating in the Middle East, are important for activists. This work shows the desire to gain an understanding of a transhistorical queer subject that existed in the Middle East's past and is connected to its present. Zeidan does not ascribe to a universal subject that has the same history, experiences, and need for rights around the world. However, he believes that a better understanding of a transhistorical Arab subject will aid activist projects in the Middle East.

In other Barra articles on the "Podium" page of Barra's website, contributors discuss contemporary scholarly works on same-sex sexuality in the Middle East such as Desiring Arabs and Unspeakable Love and analyze whether these works are helpful for LGBT activists. Barra writers also discuss how same-sex sexuality was represented throughout history in the Middle East and how those representations relate to contemporary issues. One article titled "Ideological Representations of LGBTIQ Identity in the Middle East" discusses medieval documents about same-sex sexuality written by scholars such as Ahmad al-Tifashi and Abu Nuwas and uses these documents to discuss contemporary LGBT people. The piece includes writer Jocelyn Sharlet's discussion of these texts and idea that homoerotic literature was tightly intertwined with social order and elite social norms in the past. The article also states that homoerotic discourses were common in medieval art. The unnamed writer of the piece states, "It can be argued that such discourses not only indicate the prevalence and

${ }^{117}$ Ibid. 
tolerance of same-sex sexual intimacy during the Abbasid period, but also that sexual orientation awareness/activism in the region was indigenously rooted, which contradicts arguments that alienate the character of sexual orientation activism among Arabs in the region, such as Massad's 'Re-Orienting Desire', and describes it as a western import." ${ }^{\text {"118 }}$ The author further explores why many in the Middle East reject LGBT rights and individuals and the roles of LGBT activists within the region. For instance, the author states that this rejection may be attributed to European colonialism, which saw the presence of "homosexuality" in the Middle East as a sign of depravity. ${ }^{119}$

This Barra article illustrates an important activist tactic that shows that same-sex identified people have existed in the Middle East throughout history and that same-sex sexuality is, in a sense, native to that region. This project ignores several distinctions made by historians that highlight the differences in identities and understanding of same-sex sexual behavior throughout history. Instead, the author focuses on similarities in behavior in order to construct a transhistorical gay and lesbian subject. The author also claims support for activists, arguing that "LGBTIQ activism, without the name but its activities and discourses, is not a new construct in the Middle East. This is contested in the work of poets who constructed discourses, during the Abbasid period, that allowed their participation in the public sphere and physicians who addressed the subject of same-sex sexual relations." ${ }^{120}$ In this statement, the author conflates "activism" with "awareness" with the aim of gaining legitimacy for activism as an historical project.

\footnotetext{
118 “Podium," Bara, http://www.barramag.com.

${ }^{119}$ Ibid.

${ }^{120}$ Ibid.
} 
In order to support the author's arguments in the Barra article, the author sides with Habib's essentialist views of same-sex sexuality and paints Massad as a villain of LGBT people in the Middle East. The author also argues that Massad's work ignores medieval medical texts that viewed same-sex sexuality as a special category and focuses entirely on men who engage in same-sex sexuality to the exclusion of women. While the author agrees with Massad that colonialism had a widely negative effect on same-sex practicing people in the Middle East, the author writes that the effect should not prohibit contemporary LGBT activism or ignore those who wish to identify according to their sexuality. The author suggests that LGBT identities already exist in the Middle East and those who claim these identities should not be criticized or oppressed. Though LGBT identities are new in terms of naming, the author argues that gay and lesbian subjects have always existed in the Middle East. Additionally, the main arguments in the article are placed directly in line with Habib's writing, making the author's views almost inseparable from Habib's ideas. This is illustrated through the use of quotes from Habib's work to complete the author's sentences or arguments. The author also includes Habib's arguments without any editorializing or acknowledgment that these arguments are not the author's ideas. ${ }^{121}$ In this way, the author aligns with what some may consider an established historical author in order to gain further legitimacy for the idea of an historically based and authentic same-sex sexuality in the Middle East.

Another organization that attempts to connect contemporary LGBT individuals to those who engaged in same-sex sexuality in the past is Aswat, a Palestinian lesbian organization working within Israel. Habib references Aswat in her writing as an important

\footnotetext{
${ }^{121}$ Ibid.
} 
organization that tries to educate contemporary people in the Middle East about same-sex sexuality through history. ${ }^{122}$ Aswat's website, which can be viewed in Arabic, French, and English, includes several books and articles published by its members on subjects such as the history of "homosexuality" in the Middle East, homosexuality in history, and the history of female homosexuality. A work titled, "Female Homosexuality in the Arab world" relies heavily on Habib's lectures and writing and discusses pre-modern same-sex love between both men and women. Contributors to the website state that this work was "very important for our members in refuting the ongoing accusation that they are importing western culture and practicing foreign practices." ${ }^{123}$ While this particular document is only available in Arabic, the statement by one of the website's contributors is very telling. It emphasizes the importance of the history of same-sex sexuality and love for contemporary LGBT activists and shows the need for historical continuity in present-day articulations of one's sexuality. The statement also underlines the importance of a native or authentic same-sex sexuality in the Middle East rather than a sexual identity imported from the West. These ideas underline a framework of a transhistorical subject that rejects a transcultural one. This subject relies on making connections among behaviors and identities within a culture and location throughout history rather than assume a universal subject throughout the world.

As Massad and Habib's work illustrates, the question of whether or how LGBT people from the Middle East have been influenced by those in the West is a contentious issue. In "Female Homosexuality in the Arab World" as well as other pieces on Aswat's website, contributors and members work to refute what they view as attacks on their validity,

\footnotetext{
${ }^{122}$ Samar Habib, Arabo-Islamic texts on female homosexuality 850-1780 A.D, (Youngstown, NY: Teneo Press: 2009), 11.

123 "Information and Publication," Aswat, http://www.aswatgroup.org/en/content/information-publication.
} 
which are articulated through claims of a Western influence. Additionally, by emphasizing the use of this text by "Aswat members," the essay suggests that members are part of an active effort to tell others about same-sex identified people of the past. In this manner, the past is not only helpful for LGBT people in understanding or accepting their own sexuality but in influencing the way that others think about contemporary LGBT people in the region.

In addition to discussing same-sex sexuality in "the Arab world," Aswat's website contains information and instruction about issues of same-sex sexuality and Islam. In an article titled "Islam and Homosexuality," Amal Amireh, a professor at George Mason University, links the past to the present in a distinctive way. Amireh's work deals with issues of Islamophobia, colonialism, and the tendency of those in the West towards exceptionalism when discussing Islam. She shows that throughout history, Muslims have been treated as "others" by those in the West and have been discussed in extreme terms that are opposed to Western ideas and values. She writes, "Sexuality always plays a central role in discourses of 'difference.' Sexuality has a great potential for 'othering." ${ }^{\prime 124}$ While Muslims were once seen as sexually licentious by those in the West, they are now often viewed as overly repressed. Amireh writes that this history is important in discussions of same-sex sexuality among contemporary Muslims in the Middle East. She writes that, in many ways, attempts to eradicate homophobia within Islam are actually attempts to eradicate Islam itself and that these attempts have an historical precedent that must be understood. ${ }^{125}$ Amireh's argument is useful not just in discussing the history of same-sex sexuality in the Middle East but in explaining current relationships between those who are viewed as Western and those in the

${ }^{124}$ Amal Amireh. "Islam and Homosexuality," Aswat. 2013. http://www.aswatgroup.org/en/article/islam-and-homosexuality. ${ }^{125}$ Ibid. 
Middle East. Her work is also useful to activists as a caution about working with individuals who fight for LGBT rights in the Middle East as part of a larger Islamophobic project. While Amireh may not have had Aswat members as her intended audience when she wrote her article, Aswat activists clearly saw the article as useful in educating other activists. Though Aswat contributors do not disclose their purpose in placing the article on the website, its inclusion suggests that learning more about the history of colonialism and Islamophobia is helpful for contemporary activist projects.

In addition to Amireh's important argument about colonialism and Islamophobia, her work echoes what has been previously discussed about the importance of linking same-sex identified people in the past to those in the present. She criticizes scholars who view samesex sexuality as a Western import and who see LGBT identity as something that does not belong in the Middle East. She writes, "While it is important to view sexual practices and identities in their cultural context, it is dangerous when this sensitivity to local context becomes a politics of denial." 126 In reference to scholars like Massad, she continues, "Some even went as far as to claim that those who identify as gay and lesbians in the Arab and Muslim world are 'native informants'--that is, unauthentic Arabs and Muslims, sell-outs with no representational legitimacy." ${ }^{, 27}$ Amireh writes that there are individuals in the West who do identify with LGBT labels, and the project to discount them, both from conservatives within the Middle East and liberal scholars, is harmful to LGBT people. Additionally, she writes that those who wish to identify as LGBT are equally as "authentic" as those who engage in same-sex sexuality but do not identify as LGBT. She writes that both of these

\footnotetext{
${ }^{126}$ Ibid.

${ }^{127}$ Ibid.
} 
groups "exist" and should not be ignored or mistreated. She argues that to dismiss or ignore their existence would be "deploy a politics of denial that is as pernicious as Islamophobia." "128

Amireh's critique counters Massad's argument that LGBT organizations are responsible for harming those who engage in same-sex relationships and behavior in the contemporary Middle East. Amireh argues that it is those who dismiss LGBT-identified individuals who do harm, and they must instead recognize those who do and do not identify as LGBT but who engage in same-sex sexuality. She writes that whether or not someone identifies as LGBT, they are vulnerable to prejudiced attacks. When LGBT people in the Middle East are attacked as "inauthentic" products of Western culture, all individuals who are understood to engage in same-sex behavior are vulnerable to physical and emotional attacks by those who wish to eradicate "the other." Additionally, Amireh argues that attacking LGBT-identified people as the problem duplicates the same type of discrimination that fuels Islamophobia. This analogy suggests that Massad's arguments against the Gay International are premised on discrimination that leads only to violence against LGBT people. ${ }^{129}$ One problem with Massad's arguments against LGBT activists is that he sees them as creating the gay-straight binary and causing the violence against LGBT people. However, as I have argued, that binary was already in place by the end of the nineteenth century, which was before LGBT activist groups emerged in the West or Middle East. Therefore, it seems that activist groups work as a reaction against violence that is already in place and, as Amireh suggests, to blame LGBT groups is to contribute to that violence.

\footnotetext{
128 Ibid.

129 Ibid.
} 


\section{Visibility}

The concept of visibility is also important in understanding particular narratives about same-sex sexuality and analyzing what sexual behaviors and narratives are visible or hidden within different environments. LGBT activists in the Middle East often use the word "visibility" in their literature and underline this concept as one of their primary activist goals. However, this concept has various meanings and is not used in any uniformed manner. Additionally, many activists use this term in ways that differ from dominant meanings of the term in the U.S., and it should be understood within its specific contexts. As several historical writers have illustrated, visibility is a highly debated and politically charged concept with constantly changing implications. LGBT activists in the Middle East navigates these implications and meanings differently in order to best meet the goals of their particular organizations and navigate the constraints that others in their nation present.

For some organizations, visibility refers to widespread awareness of particular issues such as violence against LGBT individuals. Some LGBT activists positioned outside of the Middle East hope to make LGBT people in the Middle East visible to the wider world in order to change what they see as problematic systems that negatively affect LGBT people. These organizations view LGBT activism and identity as global issues and see all LGBT people as connected in some way. These groups often start from the assumption that those outside the Middle East, particularly those in the West, are unaware of violence and inequalities towards LGBT people in that region. By bringing visibility to these issues, members of these organizations hope to support and encourage change for LGBT individuals and individuals who are punished for engaging in same-sex behavior. While this type of 
visibility seems to fall along Massad's critique of the missionary project, it is important to explore some of these organizations and attempt to understand activist calls for visibility.

Arsham Parsi, founder and leader of The Iranian Railroad for Queer Refugees (IRQR), works from what may be considered an insider-outsider approach in his activism and work towards visibility for LGBT issues. Parsi is an Iranian activist and queer person who fled his country after being persecuted for his LGBT activism inside Iran. After being granted asylum in Canada, he founded IRQR to support other queer Iranians who wish to gain refugee status in countries such as Canada and the U.S. ${ }^{130}$ Unlike what is typically seen as "missionary" activist work in which a Western individual seeks to help non-Western individuals and groups, Parsi may still be viewed as an insider in the Middle East. Because he is Iranian and has experienced persecution within Iran, his work may be viewed as more legitimate, and less missionary, than those who were born and live outside of Iran. However, as someone who gained asylum in the West and works with many Western activists, Parsi is very much an outsider to the lives and experiences of queer people in Iran. These distinctions are important in understanding Parsi's calls for visibility of LGBT issues in Iran.

As part of IRQR, Parsi works to gain visibility for what he views as Iran's tyrannical laws and practices against queer people. According to its website, IRQR's mission is to advocate for "queer rights and [seeks] to mainstream queer issues and connect them to the broader queer human rights discourse and civil society in Iran." ${ }^{131}$ This framework of human rights speaks to the concept of a universal subjectivity that is understood by many activists as the most helpful way to understand same-sex sexuality and "protect" those who engage in

\footnotetext{
130 "Staff and Volunteers," The Iranian Railroad for Queer Refugees, http://english.irqr.net/volunteer-staff/.

131 “What We Do," The Iranian Railroad for Queer Refugees, http://english.irqr.net/about-our-work-what-wedo/.
} 
same-sex relationships and behaviors throughout the world. Activist groups like IRQR imagine this framework as a tool for ending discrimination against all LGBT people around the globe. Though Parsi works specifically with individuals in Iran, his calls for human rights protections illustrate his understanding of Iranian queer people as connected to queer people around the world who experience love, sex, and discrimination in similar ways.

In order to bring visibility to queer issues in Iran, Parsi and others at IRQR have worked with several European, Canadian, and U.S.-based news organizations such as BBC, CBS, and CNN. ${ }^{132}$ Parsi has also been interviewed by several magazines, blogs, and newspapers in which he highlights what he views as the dire situation of queer Iranian people and the need for asylum for Iranians who have been persecuted. In one Digital Journal interview, Parsi emphasizes the dangers that many queer people face in Iran including death, torture, and rape. During the interview, Parsi highlights the case of Mehdi N., a gay man who was raped and persecuted in Iran and eventually won asylum in Germany. Parsi says, "Had Mehdi been deported back to Iran to face arrest, imprisonment, torture and most likely execution it would have saddened me beyond measure."133 Throughout the interview, Parsi makes statements such as "You can't imagine how bad it was in Iran," or "the situation for LGBTs in Iran has always been very bad" in order to highlight the severity of oppression against LGBT people there and to demonstrate how much more difficult he believes it is for LGBT people in Iran than those in the West. ${ }^{134}$

\footnotetext{
${ }^{132}$ Ibid.

133 Johnny Simpson, “Interview: Arsham Parsi of Iranian Railroad for Queer Refugees," Digital Journal. http://www.digitaljournal.com/article/279819.

${ }^{134}$ What We Do," The Iranian Railroad for Queer Refugees, http://english.irqr.net/about-our-work-what-wedo/.
} 
This type of interview works to bring visibility to issues in Iran to those outside the Middle East who know very little about the lives of LGBT individuals in Iran. By conducting interviews and working with the Western media, Parsi is able to discuss LGBT issues as much worse than LGBT oppression in the West in order to advocate for Iranian asylum seekers coming into Western nations. At the same time, Parsi appeals to a sense of universal queer subjectivity in which the presence of a global queer subject means that the lives of queer Iranians should matter to queer people in the West. Additionally, by working with media sources, Parsi is able to reach a wide audience and bring the greatest possible visibility for the issues he wishes to advocate. By placing himself as an insider in terms of LGBT issues in Iran, Parsi not only gains legitimacy for his work but brings attention to the articles in which he is featured in a way that Western activists might not.

IRQR members have also participated in many international conferences in order to advocate for LGBT rights in Iran and bring attention to inequalities towards queer Iranians. This work emphasizes the understanding that queer people around the world have a particular subjectivity and should be protected from discrimination using similar laws and treatments. These conferences have included the United Nations Human Rights Council in Geneva and the Equality forum in Philadelphia. According to IRQR's website, participation in these conferences has helped in "raising the international profile of Iranian queer issues." ${ }^{135}$ IRQR has also been involved in documentaries that highlight inequalities against Iranian queer people such as "Out in Iran" and "A Jihad for Love." These forms of activism aim to change discriminatory systems both in Iran and in the West where queer Iranians seek asylum. This form of activism differs from participation in international conferences, which aims to

135 Ibid. 
change laws, in that it seeks to reach a mass number of people through media and popular culture. IRQR reports no data on which method is more successful but hopes to advocate for LGBT rights in every way possible. ${ }^{136}$

Parsi writes that even when queer Iranians flee their country, it is difficult for them to seek asylum. Therefore, much of his advocacy tries to make it easier for queer Iranians to gain asylum. ${ }^{137}$ Additionally, because of IRQR's focus on visibility on every level of its work, IRQR activists assist only "self-identified queers" in Iran rather than all individuals who engage in same-sex behavior. While IRQR's website does not expand on this point, it is significant that those who benefit from this highly visible organization must also be visible themselves in terms of identity. Though it is apparent that in order to gain asylum, one must openly claim a certain kind of identity, it is important to note that IRQR only works with those who are visible in their queer identity. ${ }^{138}$ This distinction between those who identify as queer and those who do not may exclude many Iranians who are involved in same-sex relationships and behaviors and who may also be persecuted for their actions and relationships. Since asylum seekers must claim a lesbian or gay identity, those who are persecuted for being lesbian or gay must only appear that way or be understood as queer. For instance, when three men were executed in Iran in 2011 on charges of homosexuality, it was unclear whether or not they actually identified as gay, according to a group called Iran Human Rights. Additionally, according to a loophole in Iranian law, an individual can face criminal charges based on the "judge's knowledge" that the individual is gay with no other

\footnotetext{
${ }^{136}$ Ibid.

${ }^{137}$ Johnny Simpson, “Interview: Arsham Parsi of Iranian Railroad for Queer Refugees," Digital Journal. http://www.digitaljournal.com/article/279819.

138 "History," The Iranian Railroad for Queer Refugees, http://english.irqr.net/about-our-work-history/.
} 
evidence. ${ }^{139}$ While IRQR does not focus on these exclusions in its own work, there are many organizations and activists who see the issue of personal visibility as highly important to their work.

Bedayaa is one organization that focuses on issues of personal sexual identity and public versus private spheres of visibility. Bedayaa is headquartered in Egypt and works to create a safe space for queer people in the "Nile Valley Area," which it considers to be Egypt and Sudan. On Bedayaa's website, contributors discuss issues of queer visibility and whether or how one's sexual identity is expressed in public. For instance, in an article published on its site, there is a discussion of the evolution of public versus private same-sex behaviors in the Middle East. Bedayaa also organized a panel discussion about the "impact of clothing and colors to express our personalities and out identities in the presence of a number of gays and lesbians in Egypt." ${ }^{140}$ While the contents of this panel are not included on the site, this description is telling of the types of questions in which Bedayaa activists are interested. If certain colors and types of clothing mark one as queer, then the issue of clothing choice is really an issue of public visibility. Bedayaa does not advocate for queer individuals to make their sexuality visible in public spaces, but it does argue that queer people should have that option. Underlining these discussions is the assumption of a particular queer or gay identity that exists whether or not it is articulated in public. Additionally Bedayaa activists suggest that individuals are either heterosexual or fall into LGBT categories and that there is a gaystraight binary firmly situated within society.

\footnotetext{
${ }^{139}$ Saeed Kamall Dehghan, "Iran executes three men on homosexuality charges," The Guardian, 2011, http://www.theguardian.com/world/2011/sep/07/iran-executes-men-homosexuality-charges.

140“Bedayaa Home,” Bedayaa, http://bedayaa.webs.com/.
} 
An article on Bedayaa's website states, "The existence of social exclusion and political oppression against the people who don't fit the heteronormative traditional concept is generally based on a dangerous strategy from the political structures, which is keeping them in the dark and not letting any space for visibility of the LGBTIQ society, which is also continuously denying the existence and the relevance of the activists' fight for representation of the society and the presence of these rights in the public sphere."141 The article further states that queer people have no choice but to remain "in the closet," and that the heteronormative and discriminatory societal structure makes queer people feel ashamed of who they are and afraid of expressing themselves. ${ }^{142}$ This assumption of the Middle East as heteronormative is important considering the ways in which heteronormativity is historically situated in the region. As I previously illustrated, Ze'evi and other historical writers view heteronormativity as a result of Western Orientalism and of nationalist projects that worked to create new cultural scripts that emphasized a gay-straight binary. ${ }^{143}$ However, while old sexual scripts were silenced, same-sex love and behavior did not disappear. ${ }^{144}$ It is significant, then, that Bedayaa activists view heternormativity as a fixed condition in the Middle East rather than as a modern concept. In fact, Bedayaa writers refer to heteronormativity as a "traditional" system that LGBT activists must fight. For these

\footnotetext{
141 “Introduction to the Existing Situation," Bedayaa, http://bedayaa.webs.com/apps/blog/. ${ }^{142}$ Ibid.

${ }^{143}$ Dror Ze'evi, Producing desire changing sexual discourse in the Ottoman Middle East, 1500-1900, (Berkeley: University of California Press: 2006), 171.

${ }^{144}$ Ibid, 75-76.
} 
activists, the history of same-sex sexuality is neither visible in contemporary structures of society nor viewed as part of a traditional structures. ${ }^{145}$

In their activist projects, Bedayaa members focus on existing systems of inequality and the difficulty of gaining visibility within the Middle East. The Bedayaa article described above states that remaining "in the closet" is a consequence of an unequal societal structure. The writer does not advocate for queer Egyptians or Sudanese individuals to come out of the closet or display their identities visibly because the writer sees the burden for change with the currently unfair government and society and not with queer people themselves. However, the article does outline the ability for queer people to be visible as one of its primary goals, and visibility is clearly valued and seen as something for which activists fight. This distinction comes from contextual concerns that view 'coming out' or being physically visible as a queer person as often too dangerous for those in the region. Still, the goal of being visible, or being open about one's sexual identity in public spaces, mirrors international LGBT activist goals that see the visibility of sexual identity as a human right. This also speaks to ideas of a universal queer subject that is united under a similar consciousness and is entitled to similar "rights" that are often unmet.

On Aswat's website, contributors explicitly talk about coming out and issues of what it means for Palestinian lesbians to be open about their sexuality and relationships with other women. Aswat calls itself the "the first openly-functioning organization for Arab lesbians in the Middle East," and its visibility as an organization has led to questions of visibility among its members and other queer-identifying women in Palestine. Aswat's website contains several stories of women who have come out to their families or friends and explores the

\footnotetext{
145 "Introduction to the Existing Situation," Bedayaa, http://bedayaa.webs.com/apps/blog/.
} 
complexities of coming out for Palestinian women. While the organization does not urge women to come out, several Aswat members and contributors write about the importance of coming out for them. Additionally, in a letter from Judith Butler in response to her meeting with Aswat members, she writes, "I also appreciated how you laid out the complexity of "coming out" - a practice that is often regarded as the presupposition or even the goal of GLBTQ politics in the U.S. You relayed how the struggle with visibility is a complex one, especially where families are concerned, and you asked that we understand that activism cannot be equated with full, unprotected, visibility. ${ }^{\text {"146 }}$ This statement reflects one of the ways in which Aswat sees itself as an authentically Palestinian organization rather than one that merely reproduces the strategies and goals of organizations in the U.S. The concept of "coming out" is not understood as the only marker between native and non-native groups, but it is seen as an important distinction. Additionally, much of the stress on not coming out seems to stem from comparisons to U.S. activism in which coming out is often expected and important. Though Aswat activists view queer women, regardless of time or geographic location, as connected, they believe that local differences in experience and circumstance are important. Whether or not Aswat is doing something entirely different from U.S. LGBT activists, its members see the lack of emphasis on coming out as an important aspect of Aswat's mission.

In a panel session that contained members of Aswat and a Lebanese lesbian group called MEEM, women discussed the ways in which their activism and visibility differed from that of other activists. One panelist considered the issue of lesbian visibility as apart from issues of visible male same-sex sexuality, which is much more frequently discussed. She

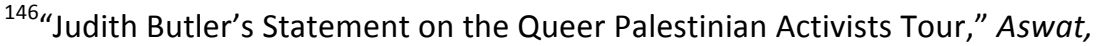
http://www.aswatgroup.org/node/913.
} 
stressed the importance of gender in both activism and systems of inequality in the Middle East and discussed some of the barriers towards visibility for queer women. She said that in the contemporary Arab world, women are not supposed to state their sexuality or even have a sexuality. She asked, "Because female sexuality in itself is restricted... how can an asexual person, with this restricted sexuality, indulge in a homosexual act in a phallocentric society?" ${ }^{147}$ In addition, the panelist said that lesbians are often left out of feminist activist groups because these groups wish to distance themselves from lesbians. Feminism is often associated with lesbianism, and these groups actively criticize lesbians in order to gain legitimacy for themselves. The panelist also said that women are often excluded from LGBT groups, which are dominated by gay men and in which women are made to conform to traditional gender roles. ${ }^{148}$ These exclusions illustrate a system where lesbians face multiple and intersecting discriminations and in which it is difficult to find allies. One of the panelists suggested that in order to create change, lesbians in the Middle East must address each of these discriminations rather than becoming lost in another group's activism. She suggested that lesbians must work from the "bottom up" within small groups of lesbians in order to form a strong activist base that pays attention to the needs of lesbians rather than rendering them invisible. ${ }^{149}$

The Aswat panel shows the importance of gender in matters of same-sex sexuality. It is no coincidence that the contemporary historians discussed in the previous chapters focus almost exclusively on male same-sex sexuality and write little about women. Apart from

\footnotetext{
147 “Towards Building a Queer and LGBTQI Women's Movement in the Arab World," Aswat, http://www.aswatgroup.org/node/2291.

${ }^{148}$ Ibid.

${ }^{149}$ Ibid.
} 
Habib's work on medieval grinders, there is little information about women who engaged in same-sex sexuality throughout history in the Middle East. This speaks to the existence of few primary documents about women, lack of interest in writing about women on the part of historians, and social structures that make women much less visible than men. The panel discussion on Aswat's website shows the desire to bring women's experiences and women's sexualities out in the open and to make lesbians visible in order to create a more equitable future. For the members of Aswat and MEEM, invisibility places lesbians "somewhere between life and death," and it is considered vital that others learn and acknowledge that they exist. Though they condemn the type of visibility in which two girls kiss on a park bench in a place where such an act can endanger one's life, they do encourage visibility as an activist group and visibility starting from within one's family or group of friends. By beginning with one's friends or family, the panelists hope to slowly change people's perceptions of lesbians and to become more visible in society. ${ }^{150}$

It is also important to understand the ways in which issues of visibility for Palestinian lesbians are related to the relationship between Palestine and Israel. The reason that Aswat is able to exist as a legal LGBT organization is because it is registered and stationed in Israel where same-sex sexuality is not illegal. In many ways, its visibility depends on Israel's stated acceptance of LGBT individuals. However, as journalist Brian Whitaker states in an article on Aswat's website, many Palestinians believe that queer people who flee to Israel are betraying their country and the LGBT rights movement in Palestine. Additionally LGBT Palestinians who make it to Israel still face risks of deportation and unfair treatment. ${ }^{151}$

\footnotetext{
${ }^{150}$ Ibid.

${ }^{151}$ Brian Whitaker, "Coming Out in Arabic," Aswat, http://www.aswatgroup.org/en/article/coming-out-arabic.
} 
However, as one panelist said, many Palestinian queer women join Israeli or Jewish LGBT groups because they believe that it is safer to disclose their sexuality there. She said women worry that in Palestinian groups, their identity will be exposed to family members or those outside the group, so they compromise by joining Israeli groups. ${ }^{152}$

These issues speak to the very specific situation of queer Palestinian women who wish to be visible but only in what they consider safe spaces. Though they see Israel as an oppressor of Palestine, many women, such as members of Aswat, make a compromise to enter Israel or join Israeli groups in order to have a perceived safe space where they can speak their identities. These acts show the importance that many activists and queer individuals place on being personally visible but only to the point where they can remain safe. In many cases, visibility is a question of visibility to whom and to what extent. Palestinian lesbians must often renegotiate how much of their identity they are willing to reveal and where they are willing to go because of their very specific social locations. Their particular position within Palestine and Israel demonstrates the complexity of visibility and the changing nature of what should and can be revealed and to whom.

Each LGBT activist and organization I studied has a different idea about visibility and how visibility as individuals, organizations, or groups can be useful in achieving one's activist goals. These activists work towards creating and demonstrating what they see as an authentic project of visibility that is specific to their social location. In some cases, as for lesbians who may feel invisible within their society, visibility may be the final goal. Additionally, ideas of visibility may be a result of LGBT activism in the West. These differences speak to nuanced understandings of activism and of words like "visibility" across

\footnotetext{
152 “Towards Building a Queer and LGBTQI Women's Movement in the Arab World," Aswat, http://www.aswatgroup.org/node/2291.
} 
various spaces. However, despite these nuances, each group seems to agree on a particular queer subject that is unified in its consciousness and lack of freedoms. Though groups like Aswat see their activist projects as dissimilar from U.S. projects, they recognizes queer people in the U.S. as sharing a particular queer identity that is recognizable throughout the world. Additionally, though activist groups in the Middle East stress local distinctions, many rely on concepts of universal inclusion such as international human rights. By employing the language of human rights and the universal existence of LGBT people, these activists work to bring legitimacy to their organizations.

\section{Tolerance}

After activists begin to make their identities visible and demonstrate that contemporary LGBT individuals are similar to those who engaged in same-sex sexuality in the past, their ultimate goal is often tolerance. For many LGBT activists, societal tolerance towards LGBT individuals is the primary goal of all activist work. This is not always the case, however, as some organizations (such as IRQR) seem to have forgone any work towards tolerance within their country and decided to work only towards issues of safety or asylum. This is also true of Iraqi LGBT, a protectionist group that runs safe houses inside Iraq for LGBT individuals. ${ }^{153}$ However, many organizations see tolerance as an issue of safety and do not believe that LGBT people can be truly safe unless there is widespread tolerance throughout their nation. Because of different types of laws concerning queer people within specific countries, questions and understandings of tolerance differ throughout the Middle East. Additionally, like the concept of visibility, tolerance is a complex issue that cannot be achieved through a straightforward method or direct mirroring of U.S. LGBT

153 “About," Iraqi LGBT http://iraqilgbt.org.uk/about. 
groups. In some cases, tolerance may be a synonym for acceptance, and in others, tolerance involves formal changes that decriminalize same-sex sexuality. However, for most activists, tolerance requires challenging those who are perceived as hating queer people or who want to see them harmed, and creating safer spaces for LGBT people to live.

Bedayaa's primary activist goal is to create a tolerant society for queer people in Egypt and Sudan. On its website, this goal is explained as, "Work towards the acceptance and normalization of homosexuality in our society and the abolition of all laws that criminalize $[$ sic $]$ directly or indirectly in Egypt and Sudan."154 Bedayaa activists illustrate the need for tolerance by showing first that Egypt and Sudan are not tolerant places for LGBT people. On Bedayaa's "Human Rights" page, activists outline a short history of injustices against LGBT individuals on the part of the government. They begin with a 1975 police raid of a private house in which two men were seized for having sex with each other and given criminal charges. Bedayaa then outlines several similar cases in which the "morality police" arrested gay men from the 1970s through the Queen Boat case where twenty-one men were given prison sentences for "debauchery and contempt of religion." 155 Though there is no law that criminalizes same-sex sexuality in Egypt, the debauchery law of 1961 is used to justify arrests of primarily gay men. So while there is no explicit anti-gay law, Bedayaa activists still must work to decriminalize same-sex sexuality because of this unofficial yet consistent use of the debauchery law. Activists also address laws in Sudan that criminalize same-sex sexuality, which are more explicit than the ones in Egypt. Sudan's Criminal Penal Code of 1991criminalizes sodomy, which can result in up to five years'

\footnotetext{
154 “Bedayaa Home," Bedayaa, http://bedayaa.webs.com/.

155 “Human Rights," Bedayaa, http://bedayaa.webs.com/humanrights.htm.
} 
imprisonment. ${ }^{156}$ Bedayaa members include this information on their site in order to underline the lack of tolerance that exists towards LGBT people in Egypt and Sudan. This intolerance, they argue, is embedded in the region's laws and reinforced by discriminatory individuals who wish to punish those who are perceived as gay.

Members of Bedayaa use the Queen Boat incident and other instances of intolerance to argue for the need for change and to imagine a different future for LGBT people in Egypt and Sudan. They write, "We hope to pass on us [sic] the memory of the Queen Boat, and we turn to the nation a more open $[$ sic $]$ and receptive the reality $[s i c]$ of homosexuality as a normal human diversity and is not a crime punishable by law." ${ }^{" 157}$ It must be noted that this incident and other incidents of homophobia described on Bedayaa's site involve gay men rather than other queer individuals. This focus on gay men is due, in part, to the visibility of men who identify as gay within Egypt and Sudan over any other queer identity. It may also involve the specific identities and interests of Bedayaa members and contributors as primarily gay men. However, Bedayaa members do hope to gain tolerance for all LGBT people and work to do so through education about gender identity and same-sex sexuality. Bedayaa's site defines concepts such as "gender," "sexual identity," and "sexual orientation" in order to educate people about issues that they see as particularly important to LGBT people. The "Gender and Sexuality" page on its site also lists stereotypes about gender and sexuality and attempts to show why these stereotypes are too simplistic. ${ }^{158}$

\footnotetext{
${ }^{156}$ Ibid.

${ }^{157}$ Ibid.

158 "Gender and Sexuality," Bedayaa, http://bedayaa.webs.com/genderandsexuality.htm.
} 
The inclusion of information about sexuality and gender issues is used to help create a more open society in which individuals in Egypt and Sudan have a better understanding of LGBT people. Bedayaa activists' assumptions seem to be that it is difficult to tolerate and accept what one does not understand, and if people are educated about LGBT issues, they will better tolerate LGBT people. Additionally, because those who discriminate against queer people or who are unsympathetic to Bedayaa's cause will most likely not visit the site, this information is intended for queer people themselves to educate others. Bedayaa activists hope to couple this type of education about LGBT people with widespread legal changes that decriminalize same-sex sexuality in order to build a more tolerant society. By encouraging both formal, legal changes and individual-level education changes, Bedayaa activists hope to encourage tolerance on every level of society. This ideal tolerant society would allow queer individuals to live without fear of physical or psychological danger or legal consequences. These goals come from the specific situation of Egyptian and Sudanese LGBT people (though particularly gay men), but they are articulated using the language and objectives of many international and U.S.-based LGBT organizations. ${ }^{159}$ This use of international LGBT groups underlines an understanding of a universal queer subject that has experienced similar discriminations throughout the world.

Massad has criticized the influence of these Western-based groups as colonizers who have disrupted local systems and practices of sexuality. Massad believes that this influence can be harmful to the Middle East as a whole and to those who engage in same-sex sexuality specifically because of the laws that are created to combat these new identities. ${ }^{160}$ However,

\footnotetext{
159 “Bedayaa Home," Bedayaa, http://bedayaa.webs.com/.

160 Joseph Massad, Desiring Arabs. (Chicago: University of Chicago Press, 2007), 173.
} 
Bedayaa activists have found international and U.S.-based activist goals and terminology to be useful in addressing discrimination and dangers for LGBT people in Egypt and Sudan that already exist. As Bedayaa activists outline on their website, queer people are vulnerable to much violence and discrimination. Additionally, their use of terminology and goals that did not originate in the Middle East is an attempt to combat this very real discrimination in what they understand as the best way possible. Massad's critiques view LGBT organizations as the problem, but LGBT organizations in the Middle East are not creating a problem that was not already pervasive. The gay-straight binary that has led to LGBT discrimination was established in the Middle East long before organizations such as Bedayaa were formed. Therefore, viewing LGBT groups as the primary or original disruptors is problematic. While Massad's arguments against LGBT groups neglect important points, it is necessary to understand that most LGBT groups in the Middle East do not address individuals who do not identify as queer in some way. These omissions may have less to do with purposeful exclusion as a belief in a particular queer identity that must be protected from discrimination. Those who do not identify as LGBT do not fit into ideas of a universal queer subject that is united under particular identities and who experiences similar discrimination. LGBT organizations do not address the ways that these individuals may be affected by LGBT activism. Thus, more work must be done towards understanding how those who do not identify as queer are affected both by discrimination against those who are perceived as queer and by LGBT organizations themselves. Groups like Bedayaa aim to promote tolerance for LGBT people in the Middle East. However, leaving out those who do not identify as queer excludes individuals who might face similar discrimination. 
Though tolerance is articulated as a formal goal on many organizations' websites, it is also discussed informally on online chat rooms and forums. Ahwaa is a bilingual online forum for LGBT youth in the Middle East to talk about issues that are important to them and “facilitate authentic, high-quality interactions." ${ }^{161}$ On Ahwaa’s online forum, there are many posts and discussion threads about homophobia and creating a more tolerant society for LGBT people in the Middle East. While it is impossible to know whether those who post are being honest about their identities, I will assume that they are being truthful for the purpose of this analysis. One thread topic that was created by an individual named Naima from the "Gulf Region of the Middle East" called "From Homophobia to High Tolerance" focuses on personal stories of homophobia. Some contributors write about their own transformations from being homophobic to tolerating LGBT people. One writer states that she once expressed disgust towards LGBT people but became tolerant towards them after her sister came out. She writes, "I helped save her life simply because I loved her. I ignored any other feelings that rose up as a result of my past prejudices- and as a person, I love myself so much more for being more tolerant to this world's differences." ${ }^{, 162}$ For Naima and others, it was knowing that her sister was queer that helped her become tolerant towards LGBT people. This transformation led her to tell her personal story and encourage others to become more tolerant of LGBT people. In this case, tolerance is equivalent to acceptance of others' differences and encouraging others to do the same.

\footnotetext{
${ }^{161}$ Nicholas Jackson, “Mideast Youth Opens Online Platform for LGBT Community, The Atlantic, http://www.theatlantic.com/technology/archive/2011/04/mideast-youth-opens-online-platform-for-lgbtqcommunity/237520/.

162“From Homophobia to High Tolerance,” Ahwaa, https://ahwaa.org/topics/8.
} 
Throughout the Ahwaa forums, there are many stories dealing with issues of homophobia and tolerance. Some individuals who have posted stories to the "From Homophobia to High Tolerance" thread write about their experiences with being accepted or rejected by their families for being queer and the difficulty of being queer in the Middle East. Some individuals discuss the best ways to achieve tolerance in their communities and nations and whether homophobic people will ever accept them. For these individuals, tolerance is defined as accepting a person as they are and not attempting to change or harm them. ${ }^{163}$ Those who post come from many different countries such as Saudi Arabia, Egypt, Lebanon, and the United Arab Emirates. Many individuals live within the Middle East but others have immigrated to countries like Canada or the U.S. Though there is diversity in the specific life experiences of each individual who posts, there is some agreement on the meaning of concepts such as homophobia, tolerance, acceptance, and support. While individuals come from different backgrounds and highlight nuances in local experiences, they understand all LGBT people to be connected and to share a similar consciousness. This understanding of LGBT people as unified in some way is what allows Ahwaa to exist and what helps those who post there to feel connected and supported by one another. For these individuals, anonymous online activism is both a way to work within an intolerant society towards a more accepting one and a way to connect with individuals who they feel are like themselves. ${ }^{164}$

Tolerance, like visibility and connecting the past to the present, is advanced through the discourse of a universal or transhistorical queer subjectivity that allows activists to feel united to one another and to what they see as their past. Some LGBT activists and individuals

\footnotetext{
163 Ibid.

164 “Homophobia in Local Media," Ahwaa, https://ahwaa.org/topics/40.
} 
view Western tactics as impractical for those in the Middle East. Other activists illustrate local concerns that may not be an issue for those outside the Middle East or those within other regions of the Middle East. These concerns deal with issues of corrective rape for lesbians and imprisonment for some gay men. While many activists understand intersecting oppressions depending on one's social location, they are united through issues of sexuality. When they speak of a tolerant society, they wish for tolerance from many forms of discrimination but stress freedom from discrimination towards all LGBT people as their unified purpose.

\section{Israel/Palestine: Pinkwashing and Homonationalism}

Thus far, I have discussed LGBT activists in the Middle East who rely on a universal or transhistorical subjectivity to further their activist projects. Those in many LGBT organizations privilege LGBT-rights as their primary issue but work against many forms of oppression. These activists also appropriate historical writing that deals with practices of same-sex sexuality throughout history. In contrast, the activists and individuals who identify as Palestinian do not state LGBT-rights as their primary means of organizing. Though they often seem to understand a specific queer subjectivity, they have a dual purpose of creating a more equal and inclusive society for LGBT people and of liberating Palestinian people who are oppressed by Israeli structures. Additionally, the scholarship concerned with Palestinian groups differs from previously discussed scholarship in its focus on issues of homonationalism and pinkwashing.

With the exception of Helem, nearly all of the legally sanctioned LGBT activist organizations in the Middle East are headquartered in Israel. Like Aswat, many Palestinian organizations operate within Israel because of the expectation of greater freedoms and 
visibility that they will have there. However, as the Israeli government continues to occupy Palestine, the presence of LGBT activists in Israel is incredibly complicated. Recent scholarship on these complications has centered on concepts of pinkwashing and homonationalism. Scholars Jasbir Puar and Maya Mikdashi describe pinkwashing as "the process by which the Israeli state seeks to gloss over the ongoing settler colonialism of historic Palestine by redirecting international attention towards a comparison between the supposedly stellar record of gay rights in Israel and the supposedly dismal state of life for LGBTQ Palestinians in Occupied Palestine." ${ }^{165}$ One of the concerns associated with pinkwashing is that it paints Israel as a progressive nation and allows it to get away with widespread discrimination. For instance, while Israel recognizes same-sex marriages performed outside of Israel, it prohibits Palestinians and Israelis from marrying. Puar and Mikdashi write that this latter point is normalized in favor of the push for international LGBT rights. ${ }^{166}$ Under the assumption of LGBT rights, queer Palestinians are protected in terms of their right to love and have sex with the person they desire unless that person is Israeli, but they do not have the right to political freedoms because they are still Palestinian. ${ }^{167}$

The related concept of homonationalism refers to the practice of evaluating and judging a nation according to how its LGBT members are treated. Mikdashi writes that homonationalism is "the idea that LGBTQs the world over experience, practice, and are motivated by the same desires." ${ }^{\text {168 }}$ Homonationalism also assumes that LGBT politics are

\footnotetext{
165 Jasbir Puar \& Maya Mikdashi, "Pinkwashing and Pinkwatching: Interpenetration and Discontents," 2011, Jadaliyya. http://www.jadaliyya.com/pages/index/6774/pink watching-andpinkwashing_interpenetration-and. 
grounded in a stable identity and can be supported through the same human rights framework. Hillary Clinton employed this concept when she referred to "gay rights" as "human rights."169 Mikdashi writes, "Homonationalism produces normative homosexuality in the same fashion that normative 'heterosexuality' continues to be shaped and regulated internationally through the interventions of human rights corporations, international funding and research agencies, and the foreign and domestic policies of states." ${ }^{, 170}$ She writes that these homonormative articulations occur within the neoliberal framework of policy suggestions rather than acts of military or governmental force, and are therefore more difficult to see. However, she argues that these neoliberal articulations work to produce and control a specific political subject throughout the world. Additionally, she writes that activists in the Middle East feel that they must "partake" in homonationalism in order to be taken seriously and to be supported by powerful white gay individuals with the economic and political resources that the activists desire and require. ${ }^{171}$

Mikdashi refers to those who critique pinkwashing as "pinkwatchers" and argues that pinkwatchers produce similar narratives as pinkwashers. She points to Palestinian activist organizations such as Palestinian Queers for BDS, alQaws, and Pinkwatching Israel as pinkwatching organizations that actually use homonationalism as a strategy to promote justice for queer Palestinians. She writes that activists in these organizations "walk the precarious line between the daily realities of LGBTQ discrimination and oppression and the dangers of separating and elevating that particular discrimination over the terrain of

\footnotetext{
${ }^{169}$ Ibid.

${ }^{170}$ Ibid.

${ }^{171}$ Ibid.
} 
interconnected oppressions that forms, in part, what it means to be Palestinian." ${ }^{172}$ Mikdashi also writes that these pinkwatching activists attempt to respond to Israel's claim to progress despite its extensive abuses by using the same language of "gay rights" that is used to justify abuses against Palestinian people. ${ }^{173}$ For instance, pinkwatching organizations continue to emphasize the same rights as pinkwashers such as the right to same-sex marriage and the right to serve in the military as rights for which activists should particularly fight.

Additionally, Puar and Mikdashi argue that pinkwatching organizations often take part in "lowest common denominator politics" by focusing their efforts on pinkwashers in relation to sexuality rather than analyzing wider racial and colonialist systems. Finally, they argue that while pinkwatchers focus on pinkwashing within Israel, they ignore the pinkwashing that occurs in the U.S., failing to consider the wider context in which pinkwashing occurs. Puar and Mikdashi are not dismissive of pinkwatching groups in their work, and in fact find them important and necessary, but hope that these criticisms will encourage both activists and scholars to be careful with the ways in which they construct narratives and employ homonationalism. $^{174}$

An analysis of Palestinian Queers for BDS, Pinkwashing Israel, and alQaws’ English websites shows that Puar and Mikdashi's critiques are not necessarily accurate. Contrary to the scholars' assertions, these Palestinian groups do criticize the U.S. for its complicity in pinkwashing Israel. For instance, Palestinian Queers for BDS activists criticized the U.S.-

\footnotetext{
${ }^{172}$ Ibid.

${ }^{173}$ Ibid.

${ }^{174}$ Jasbir Puar \& Maya Mikdashi, “Pinkwashing and Pinkwatching: Interpenetration and Discontents," 2012, Jadaliyya. http://www.jadaliyya.com/pages/index/6774/pink watching-and-pinkwashing_interpenetrationand.
} 
based Equality Forum's decision to highlight an Israeli LGBT leader in its 2012 summit in Philadelphia. They wrote that they were appalled that the Equality Forum was "partnering with the Israeli Embassy in Washington and the Israeli Ministry of Tourism in promoting the Tel Aviv gay tourism agenda. Even more disturbing is the Equality Forum's willingness to provide Israel with a platform to market itself as a state that protects human rights." ${ }^{175}$ The activists then accused the Equality Forum of being complicit in Israel's attempts to promote itself as a safe-haven for LGBT people while oppressing and abusing countless Palestinian people. ${ }^{176}$ Both alQaws and Pinkwatching Israel were involved in similar campaigns that highlighted the U.S.'s complicity in Israel's pinkwashing project.

Another aspect of Puar and Mikdashi's critique deals with the way in which pinkwatching groups focus their efforts too narrowly on issues of sexuality rather than understanding the wider systems of discrimination. ${ }^{177}$ However, a careful analysis of pinkwatching groups shows that, though these organizations strongly focus on sexuality, their activism also addresses multiple forms of intersecting discriminations. Rather than focusing on sexuality as a singular issue, groups use the concept of pinkwatching as a lens to understand issues of colonialism and racism that affect occupied Palestinian people. While Israel promises rights to Palestinian queer people, pinkwatching groups show that these promises do not secure Palestinians' safety or provide for other freedoms. For instance,

\footnotetext{
${ }^{175}$ Palestinian Queers for BDS.

${ }^{176}$ Ibid.

177 Jasbir Puar \& Maya Mikdashi, “Pinkwashing and Pinkwatching: Interpenetration and Discontents," 2012, Jadaliyya. http://www.jadaliyya.com/pages/index/6774/pink watching-and-pinkwashing_interpenetrationand.
} 
Pinkwatching Israel critiques Israeli groups like Gay Middle East.com for reproducing structures of colonialism and racism that work to harm all Palestinian people. ${ }^{178}$

Palestinian activists also highlight the multiple discriminations towards queer people and activists around the world and the particular difficulties involved in doing boycott, divestment, and sanctions activism from different social locations. They reject those who they view as reproducing colonialist structures and take an intersectional approach to their work. While LGBT and national issues unite them, they show that no single form of oppression can exist alone. ${ }^{179}$ Palestinian activists' acts of rejecting those who have promised them rights as queer people but not as Palestinians are important and powerful. Additionally, while many groups must work against the discrimination and hatred from people in their own countries, groups like alQaws work to support and liberate their own people despite Palestine's lack of protections for LGBT individuals. These groups see fairness and freedoms in a holistic sense and do not believe that Palestinian LGBT individuals can be free while Palestinians are under Israeli occupation.

Finally, the claim that activists" use of "gay rights" and "human rights" reproduces the language of pinkwashing groups is significant given the understanding of most LGBT activists in this chapter of a universal or transhistorical queer subject. Though pinkwatching groups differ from other LGBT groups in the region, these groups also understand a particular queer subject as one that is meaningful and which experiences certain shared prejudices throughout the world. For instance, activists in Pinkwatching Israel refer to the

\footnotetext{
178“Gay Middle East.com: You do not speak for us," Pinkwatching Israel,http://www.pinkwatchingisrael.com/portfolio/gaymiddleeast-com-you-do-not-speak-for-us/.

179 “Panel on: What is Queer BDS?”Pinkwatching Israel, http://www.pinkwatchingisrael.com/2012/12/21/wsfpanel-2/.
} 
“global LGBT movement" that promotes "queer-powered calls against pinkwashing."180 These activists see the global movement as somewhat unified in its goals and understanding of queerness. Pinkwatching Israel also encourages global queer activism and includes activists from places like Canada as similarly motivated as queer activists in Palestine in their fight against pinkwashing. ${ }^{181}$ Similarly, alQaws activists write about the "beautiful spirit of global solidarity" in its discussion of its political activism. ${ }^{182}$ However, given the specific concerns of pinkwatching groups, it does not seem that these groups are simply reproducing the language of pinkwashing individuals.

As I have shown, members of groups like alQaws and Pinkwatching Israel are highly critical of colonialist and racist tactics by those in Israel and the U.S. and fight against many forms of oppression. Their understanding of a universal queer subject is not an attempt to erase local concerns or abuses. Rather, it is an acknowledgement that throughout much of the world, people who identify as LGBT experience violence and discrimination because of their LGBT status, which often intersects with other forms of oppression. It is also an understanding that in order to work towards many activist goals, it is helpful to gain the support of others who experience discrimination in similar ways. By calling on a global LGBT movement, alQaws and other groups do not wish to conceal abuses that occur in the name of LGBT rights or argue that all LGBT people are the same with no understanding of context. Just like the other LGBT activists analyzed in this chapter, pinkwatching organizations form groups and communities with one another in response to discrimination they experience or see around them. They view the universal queer subject as important in

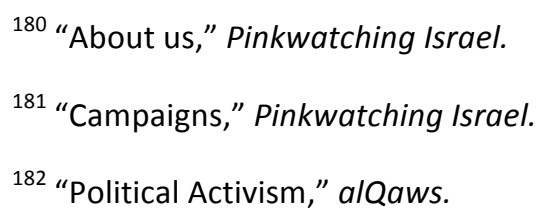


organizing and attempting to create change in their communities or personal lives while carefully defining regional distinctions and structural systems that affect LGBT individuals in diverse ways. 


\section{CONCLUSION}

When examining LGBT rights organizations, it is important to analyze what the activists have to say about themselves and the sorts of activism in which they are involved. While much academic criticism is useful in understanding large issues of queer activism, homonationalism, and discrimination, it is equally as important to understand the narratives that LGBT groups construct about themselves. One of the most important aspects of this thesis was to analyze specific activist groups and projects and to demonstrate nuances among these groups. Though I argue that LGBT groups as a whole claim a transhistorical queer subject that is often based in a human rights framework, I also work to make distinctions between each group. In this way, I treat the study of activist groups and academic projects similarly by trying to understand specific arguments, works of writing, and frameworks. Through Aswat and The Iranian Railroad for Queer Refugees may be interested in human rights as a protection against discrimination, the members and social locations of these groups are very different. By outlining these differences, I afford these groups the same level of importance that I give to historical scholars like Ze'evi or Najmabadi.

The comparative nature of this work also helps provide both LGBT activists and scholarly historical writers a similar level of importance. I have attempted to allow a fair amount of space and attention to activist projects within and outside the academy. There is an intentional feminist effort to ensure that LGBT voices in the Middle East are heard and taken seriously. Additionally, this comparative work offers a fuller picture of understandings of 
same-sex sexuality in the Middle East. A focus only on academic criticism or activist work would be to enforce an academic/activist divide that provides an incomplete picture of LGBT issues in the region. Academics and activists are often involved in similar work to educate others about the past and explain the ways in which the present has been shaped. While academics and activists come from different knowledge- forming positions, they are often part of deeply connected projects. Therefore, it is crucial to examine academics who discuss contemporary LGBT activists and activists themselves in order to better understand these connections.

While this work is incomplete in many ways, it is also a descriptive project about a still evolving social movement and its connections to history and authority of history. The activist project described among contemporary historical scholars is one that is specific to the last several years. Though the particular work described here among scholars is influential, it is also subject to change over time. Therefore, it is crucial for scholars to trace these changes and to analyze new historical writings on same-sex sexuality that may offer varying perspectives. Sexuality studies in the Middle East make up a growing field of scholarship. As it grows, it will be important to understand how this scholarship influences those outside the academy and how the scholarship is used. Additionally, the goal of many LGBT activists is to change their communities and countries in order to form safer spaces and more freedoms for queer people. Members of these organizations use the tools that are available to them, such as the language of universal rights, in order to work towards these changes. Though these tools are important for contemporary activists, they are constantly changing. Therefore, scholars must continue to examine these changes and not assume a stable activist position or project. 
On January 28, 2014, Judge Naji al-Dahdah said in a Lebanese court that sex between a trans woman and a man could not be seen as unnatural and was not prosecutable. This was a landmark ruling in the face of Article 534, which has long been used to criminalize samesex relationships. ${ }^{183}$ Prosecutors of this case, who conflated gender identity with sexual orientation, attempted to use Article 534 to argue that "unnatural sexual intercourse" had occurred. The judge ruled that Article 534 could not be used in this case and drew on a 2009 case in which Judge Mounir Suleiman said that same-sex relationships are not unnatural. In this earlier case, Judge Suleiman had said, "Man is part of nature and is one of its elements, so it cannot be said that any one of his practices or any one of his behaviors goes against nature, even if it is criminal behavior, because it is nature's ruling." ${ }^{184}$ This ruling has been cited as a result of Helem's legal campaign to annul Article $534 .{ }^{185}$ In the 2014 case, Judge al-Dahdah expanded this idea to gender identity and said that a person's gender is not necessarily what has been assigned at birth. ${ }^{186}$ Though this case does not end the use or existence of Article 534, it is significant in its discussion of both same-sex sexuality and gender identity, and it may be used in future cases.

While this recent case may represent an important advance in legal understandings of LGBT people in Lebanon, it is clear that there are still many misunderstandings around

\footnotetext{
${ }^{183}$ F.V.T., "Laws of Nature," The Economist, March 14, 2014, http://www.economist.com/blogs/pomegranate/2014/03/gay-rights-lebanon

${ }^{184}$ Helen McDonald, "What the Headlines Missed: Landmark Ruling in Lebanon Advances Trans* Rights Too," Autostraddle, March 27, 2014.

${ }^{185}$ Victoria Kim, “Gays in Lebanon Just Snagged a Major Victory,” PolicyMic, March 5, 2014, http://www.policymic.com/articles/84401/gays-in-lebanon-just-snagged-a-major-victory.

${ }^{186}$ Helen McDonald, "What the Headlines Missed: Landmark Ruling in Lebanon Advances Trans* Rights Too," Autostraddle, March 27, 2014
} 
issues of same-sex sexuality. First, when the prosecutors of the case attempted to use Article 534 in an instance of what they thought of as same-sex sexuality, they were ignoring the defendant's trans identity and fact that for those involved, this was not a same-sex relationship. Second, though the judge was instrumental in calling out abuse of the law, he did not refer to the defendant with her preferred pronouns. The judge first referred to her as a "male," and then as "he/she." ${ }^{, 187}$ Additionally, while Autostraddle and Policymic refer to this decision as a landmark for all LGBT people, most news organizations saw this as a victory primarily for same-sex couples. In addition to leaving out trans voices and identities, this idea misunderstands same-sex identity and behavior and conflates gender identification and performance with same-sex sexuality. It also highlights similar confusion about LGBT people in the Middle East and the U.S.

This thesis has examined issues of same-sex sexuality in the Middle East that have been articulated by those inside and outside the academy. Through the process of linking academic and activist projects as part of a similar framework, this work also makes connections between same-sex sexuality in the Middle East and the West. LGBT activists in the Middle East demonstrate how their work is connected to that of activists throughout the world through an understanding of a universal or transhistorical queer subject and language of human rights. Though they pay close attention to specific cultural understandings and constructions of sexuality, activists argue that same-sex sexuality exists throughout time and space and that LGBT individuals are often targeted for violence and discrimination despite their social location. Additionally, Ze'evi and other historians show that understandings of same-sex sexuality in Middle East have long been influenced by sexual behavior and desire

${ }^{187}$ Ibid. 
in Europe. These connections demonstrate that strict divisions need not be made between the Middle East and West because individuals in both regions have long shared understandings and practices of same-sex sexuality.

Historical scholarship about same-sex sexuality has changed enormously since the Orientalist works of the late nineteenth and early twentieth century that saw sexuality in the Middle East as exceptional. Contemporary historical writers view same-sex sexuality in the Middle East with thoughtful attention for local construction and meaning and with respect to the past's autonomy. Though these writers often study the past for the sake of scholarship itself, their works are influential and can be used as powerful tools towards creating valid identities and curbing discrimination for contemporary LGBT people. This thesis only begins to outline the connections between contemporary historical scholarship and LGBT activists in the Middle East. More scholarship must be done to understand how historical work is appropriated and whether LGBT people find this work validating for their own identities. However, I hope that I have made an important step in connecting academic and activist projects and demonstrating the necessity of these connections for many LGBT people. 


\section{REFERENCES}

“About.” Iraqi LGBT. http://iraqilgbt.org.uk/about

“About us.” Pinkwatching Israel. http://www.pinkwatchingisrael.com/about-us/

Amireh, Amal. "Islam and Homosexuality," Aswat. 2013.

http://www.aswatgroup.org/en/article/islam-and-homosexuality.

Andrews, Walter G., and Mehmet Kalpakl1. The age of beloveds: love and the beloved in early-modern Ottoman and European culture and society. Durham: Duke University Press, 2005.

Babayan, Kathryn, and Afsaneh Najmabadi. Islamicate sexualities: translations across temporal geographies of desire. Cambridge, Mass: Center for Middle Eastern Studies of Harvard University, 2008.

“Bedayaa Home.” Bedayaa. http://bedayaa.webs.com/.

“Campaigns.” Pinkwatching Israel. http://www.pinkwatchingisrael.com/campaigns/.

Chan, Sewell. "Iranian Leader, Calling Introductory Remarks Insulting, Addresses

Columbia.” New York Times. September 24, 2007. http://cityroom.blogs.nytimes.com /2007/09/24/protests-at-columbia-over-iran-leaders-speech/.

“Coming Out in Arabic.” Aswat. http://www.aswatgroup.org/node/591.

Deveaux, Monique. "Feminism and empowerment: A critical reading of Foucault." Feminist Studies. 20 (2) (1994). 
Dehghan, Saeed Kamall ."Iran executes three men on homosexuality charges," The Guardian, 2011, http://www.theguardian.com/world/2011/sep/07/iran-executes-menhomosexuality-charges.

"Do the People of this Website Publically Support LGBT Rights." Ahwaa. https://ahwaa.org/topics/574.

El-Rouayheb, Khaled. Before homosexuality in the Arab-Islamic world, 1500-1800. Chicago: University of Chicago Press, 2005.

"From Homophobia to High Tolerance." Ahwaa. https://ahwaa.org/topics/8.

Foucault, Michel. The history of sexuality, Vol. 2: The Use of Pleasure. Random House Digital, 2012.

—. The history of sexuality. Vol. 1. New York: Vintage, 1990.

—.Discipline and punish: the birth of the prison. New York: Vintage Books, 1995.

F.V.T. "Laws of Nature.” The Economist. March 14, 2014.

http://www.economist.com/blogs/pomegranate/2014/03/gay-rights-lebanon

"Gay Middle East.com: You do not speak for us." Pinkwatching Israel.

http://www.pinkwatchingisrael.com/portfolio/gaymiddleeast-com-you-do-not-speak-for-us/.

Grafton, Anthony. "History under attack," American History Association. Last modified,

Dec. 28, 2010. http://www.historians.org/perspectives/issues/2011/1101/1101pre1.cfm.

"Gender and Sexuality." Bedayaa. http://bedayaa.webs.com/genderandsexuality.htm

Habib, Samar. Female homosexuality in the Middle East: histories and representations. New York: Routledge, 2007.

-.Habib, Samar. Arabo-Islamic texts on female homosexuality 850-1780 A.D. Youngstown, NY: Teneo Press. 2009. 
"Homophobia in Local Media." Ahwaa. https://ahwaa.org/topics/40.

"Human Rights." Bedayaa. http://bedayaa.webs.com/humanrights.htm.

"Illinois Governor Wants to 'Fumigate' State's Government." CNN.com. January 30, 2009. http://edition.cnn.com/2009/POLITICS/01/30/illinois.governor.quinn/.

"Information and Publication." Aswat. http://www.aswatgroup.org/en/content/informationpublication.

"Introduction to the Existing Situation." Bedayaa. http://bedayaa.webs.com/apps/blog/. Jackson, Nicholas ."Mideast Youth Opens Online Platform for LGBT Community. The Atlantic, http://www.theatlantic.com/technology/archive/2011/04/mideast-youth-opensonline-platform-for-lgbtq-community/237520/.

Kim, Victoria. "Gays in Lebanon Just Snagged a Major Victory.” PolicyMic. March 5, 2014. http://www.policymic.com/articles/84401/gays-in-lebanon-just-snagged-a-major-victory. Lee, Richard E., Immanuel Maurice Wallerstein, and Volkan Aytar. Overcoming the two cultures: science versus the humanities in the modern world-system. Boulder, Colo:

Paradigm Publishers, 2004.

"Lesbians in Egypt, Where are you?" Ahwaa. https://ahwaa.org/topics/795.

Massad, Joseph. Desiring Arabs. Chicago: University of Chicago Press, 2007.

McDonald, Helen. "What the Headlines Missed: Landmark Ruling in Lebanon Advances Trans* Rights Too.” Autostraddle, March 27, 2014.

Mikdashi, Maya, “Gay Rights as Human Rights: Pinkwashing Homonationalism.” Jadaliyya, 2011, http://www.jadaliyya.com/pages/index/3560/gay-rights-as-human-rights_pinkwashinghomonational. 
Najmabadi, Afsaneh. Women with mustaches and men without beards: gender and sexual anxieties of Iranian modernity. Berkeley: University of California Press, 2005.

“Our Work.” Helem. 2013. http://www.helem.net/node/62.

"Panel on: What is Queer BDS?"Pinkwatching Israel, http://www. Pinkwatchi ngisrael.com /2012/12/ 21/wsf-panel-2/.

Philp, Mark. "Foucault on Power: A Problem in Radical Translation?" Political Theory.11 (1): 29-52 (1983).

"Podium." Barra. http://www.barramag.com.

Puar, J. \& Mikdashi, M. "Pinkwashing and Pinkwatching: Interpenetration and Discontents." Jadaliyya, 2012. http://www.jadaliyya.com/pages/index/6774/pink watching-andpinkwashing_interpenetration-and.

Said, Edward W. Reflections on exile and other essays. Cambridge, Mass: Harvard University Press, 2000.

Simpson, Johnny, "Interview: Arsham Parsi of Iranian Railroad for Queer Refugees.” Digital Journal. http://www.digitaljournal.com/article/279819.

Sprague, Joey. 2005. Feminist methodologies for critical researchers: bridging differences. Walnut Creek, CA: AltaMira Press.

"Staff and Volunteers," The Iranian Railroad for Queer Refugees. http://english.irqr.net/volunteer-staff/.

“Towards Building a Queer and LGBTQI Women's Movement in the Arab World," Aswat, http://www.aswatgroup.org/node/2291.

Weeks, Jeffrey. Making sexual history. Cambridge, UK: Polity Press, 2000. 
"What We Do." The Iranian Railroad for Queer Refugees. http://english.irqr.net/about-ourwork-what-we-do/.

Whitaker, Brian. "Coming Out in Arabic." Aswat.

http://www.aswatgroup.org/en/article/coming-out-arabic.

Ze'evi, Dror. Producing desire changing sexual discourse in the Ottoman Middle East, 15001900. Berkeley: University of California Press, 2006.

Zeidan, Tarek. "Raging Blind.” Barra. no. 05. http://www.barramag.com/wpcontent/uploads/2012/11/Barra-005.pdf. 


\section{CURRICULUM VITAE}

Lauren Copeland

1501 Shelburne Circle, Unit 303

Louisville, KY 40208

Lecope01@louisville.edu

Education - University of Louisville, Louisville KY; M.A. in Women's and Gender Studies; Aug 2012-present; planned graduation date May 2014

Thesis: Academics and Activism: A Comparative Study of

Contemporary Historical Writings on Same Sex Sexuality and LGBT

Activists in the Middle East

Malissa Taylor, director

- University of Kentucky (UK), Lexington KY; Gender and

Women's Studies Graduate Certificate; Aug 2011-May 2012; graduation date May 2012

- University of Kentucky (UK), Lexington KY; Dean's List; B.A.in Journalism; B.A. in Anthropology; Aug 2005-Dec 2009; graduation date Dec 2009

$\begin{array}{lll}\text { Areas of } & \text { - } \text { Global LGBT movements } \\ \text { Academic } & \text { - The appropriation of the past in LGBT organizing } \\ \text { Interest and } & \text { - The relationship between social activism and the academy } \\ \text { Research } & \text { - History of sexuality in the Middle East } \\ & \text { - LGBT immigrants and global violence against LGBT individuals } \\ & \text { - Globalization and transnationalism } \\ & \text { - Homonationalism and pinkwashing }\end{array}$

Related Experience
-Akers Graduate Assistantship; August 2013-present

I work at the Anne Braden Institute to evaluate the Healing History Academy, a community program that promoted racial healing in Louisville. I talk with program participants, revisit the materials used and generated, and try to understand the program's overall impact in reducing structural racism and promoting racial healing. I also work with my department chair, Nancy Theriot in developing community-based internship programs for undergraduates. 
-Research Assistant; January 2012-May 2012

I worked with Cristina Alcalde, professor of gender and women's studies, in analyzing research on immigration attitudes and experiences among first year students.

Leadership Graduate Student Union, University of Louisville; August 2013- present

And Service Departmental representative and member of grievance committee for graduate students

Discuss best use of research funds for graduate students.

Graduate Student Council; August 2013-present

Departmental representative. Work to improve conditions at the

University of Louisville for graduate students.

East Seventh Street Center, Lexington KY; Dec 2010-May 2012

Tutor and Mentor

Worked with children K- $8^{\text {th }}$ grade on reading and schoolwork. Created games and activities for children

Village Branch Library, Lexington KY; Aug 2009-May 2010

Tutor and Mentor

Worked in homework room each week with ESL children K- $8^{\text {th }}$ grade.

Created games and activities for children

K Week Leader, Lexington KY; Summer 2008-2010

Event organizer and mentor for incoming freshman. Including leading discussions on race and literature

VIP Center, Lexington KY; Spring, 2010

SEEDS of Hope organizer

Worked with VIP Center at UK to create specialized bystander training program

Kentucky Refugee Ministries, Lexington KY; Jan 2009-Jan 2010

Tutor and Mentor

Worked with newly arrived refugee child from Nepal and her family every week. Taught English and helped with schoolwork. Also aided the family in becoming accustomed to life in Lexington

Morton Middle School, Lexington KY

Volunteer with Family Resource Center; May-July 2009

Worked with school social worker

Standardized Testing accommodations; May 2009- May 2011

Work with ESL students who need accommodations during standardized tests

Cassidy Elementary School, Lexington KY; June-July 2009

Families and Children Educating (FACE) volunteer tutor and mentor in camp for newly arrived refugee children

Greenthumb Environmental Club, Lexington KY; Jan 2006-May 2008

Educated students about helping environment, worked with community to develop greener planet 
Kentucky Kernel
Assistant Opinion Editor, Lexington, KY; Jan-May 2009

- Developed weekly editorials for editorial board

- Designed page layout

- Edited copy and proofread

- Verified facts and data for news stories

- Was responsible for finding columnists and making sure writers met deadlines

Reporter, Lexington, KY; Jan 2006- Aug 2009

-Researched and reported stories ranging from features of local activists to student opinions of prescription drugs on campus

-Proficient in InDesign, Photoshop and Quark
Continuing Education

Study Abroad South Africa: May, 2013- June, 2013. Interviewed women who were anti-apartheid activists. Spoke with members of anti-violence organizations in Cape Town. Met with community healers. Contributed to an online journal about the trip.

Conferences $\quad$ Coalition of Urban and Metropolitan Universities; Oct 27-29 2013

Contributed to a round table discussion about transforming and sustaining communities through partnerships through my study abroad trip to South Africa.

-Assessment of English as a Second Language Services and Client

Populations, Lexington KY; Nov 2009

Contributed to literature that assessed accessibility and limitations of ESL classes for immigrant and refugee populations in Lexington 
-Healthy Foods, Local Farms Conference, Louisville KY; Aug 2006; Aug 2007; Oct 2012

Workshops focused on such topics as sustainable agriculture and migrant farming 